ALD Precursors

\title{
Controlling the Thermal Stability and Volatility of Organogold(I) Compounds for Vapor Deposition with Complementary Ligand Design**
}

\author{
Matthew B. E. Griffiths, ${ }^{*[a]}$ Zachary S. Dubrawski, ${ }^{[a]}$ Goran Bačić, $^{[\mathrm{a}]}$ Achini Japahuge, ${ }^{[\mathrm{a}]}$ \\ Jason D. Masuda, ${ }^{[b]}$ Tao Zeng, ${ }^{[a]}$ and Seán T. Barry ${ }^{[a]}$
}

\begin{abstract}
Atomic layer deposition (ALD) of gold is being studied by multiple research groups, but to date no process using non-energetic co-reactants has been demonstrated. In order to access milder co-reactants, precursors with higher thermal stability are required. We set out to uncover how structure and bonding affect the stability and volatility of a family of twelve organogold(I) compounds using a combination of techniques: X-ray diffraction (XRD), thermogravimetric analysis (TGA), differential scanning calorimetry (DSC), and density functional theory (DFT). Small, unsubstituted phosphonium ylide ligands bind more strongly to $\mathrm{Au}(\mathrm{I})$ than their silyl-substituted analogues, but the utility of both these ligands suffers due to their poor volatility and substantial thermal decomposition. Pentafluoro-
\end{abstract}

phenyl $\left(\mathrm{C}_{6} \mathrm{~F}_{5}\right)$ is introduced as a new, very electronegative ligand for gold vapor deposition precursors, and it was found that the disadvantage to volatility due to $\pi$-stacking and other intermolecular interactions in the solid state was overshadowed by dramatic improvements to kinetic and thermodynamic stability. We introduce a new figure of merit to compare and rank the suitability of these and other complexes as precursors for vapor deposition. Finally, DFT calculations on four compounds that have high figures of merit show a linear correlation between the gold-coordinative ligand bond dissociation energies and the observed decomposition temperatures, highlighting and justifying this design strategy.

\section{Introduction}

Atomic layer deposition (ALD) is a chemical vapor deposition (CVD) technique that relies on specific surface chemistries to force film growth into a self-limiting layer-by-layer regime. ${ }^{[1]}$ Films deposited by ALD are highly conformal to substrate geometry, and sub-nanometer thickness control can be easily achieved by changing the number of sequential reactant exposures (i.e., cycles). Recently, two different ALD processes to deposit gold metal were reported using organogold(III) precursors: one by our group using oxygen-plasma and water as coreagents, and the other by Mäkelä and co-workers using ozone. ${ }^{[2,3]}$ While both processes were effective at depositing gold metal with high growth rates at low temperatures, they inherently suffer similar limitations in their scope. Firstly, thermal instability due to recombination of energetic oxygen species prevents high-degree of thickness uniformity of the films down high-aspect ratio trenches, vias, or tortuous geome-

[a] Department of Chemistry, Carleton University, 1125 Colonel By Drive, Ottawa, Ontario, K1S 5B6, Canada E-mail: mbgriffi016@gmail.com carleton.ca/barrylab

[b] Department of Chemistry, Saint Mary's University, 923 Robie Street, Halifax, Nova Scotia, B3H 3C3, Canada

[**] A previous version of this manuscript has been deposited on a preprint server (https://doi.org/10.26434/chemrxiv.8038973.v1).

$\square$ iD Supporting information and $O R C I D(s)$ from the author(s) for this article are available on the WWW under https://doi.org/10.1002/ejic.201901087. tries. ${ }^{[4,5]}$ Secondly, many substrates are incompatible with oxygen plasma or ozone and are therefore incompatible with these processes.

The strategy most often used for selecting viable compounds to use as new potential ALD precursors is to turn to previous literature; pick the best candidates based on volatility, thermal stability, and reactivity; and try to adapt them for use in an ALD process. While this was fruitful for gold, as shown by both reported processes using previously reported CVD precursors, ${ }^{[6-8]}$ this selection process only returns a handful of molecules that are often quite different from one another in their structure and chemistry. ALD precursor design for other materials is quite mature in some cases and has been proven to be a useful tool in accelerating process development for $\mathrm{Cu}, \mathrm{Ru}, \mathrm{Co}$, $\mathrm{Ni}$, and many other metallic films. ${ }^{[9,10]}$ As such, we felt that a thorough study on the fundamental factors that govern thermal stability and volatility would be useful in the development of new gold ALD precursors.

Many $\mathrm{Au}(\mathrm{I}) \mathrm{CVD}$ precursors decompose below $200{ }^{\circ} \mathrm{C} .{ }^{[11]}$ By comparison, the current two ALD precursors undergo thermolysis: at $140{ }^{\circ} \mathrm{C}$ for trimethylgold(III) trimethylphosphine (A) and at $220{ }^{\circ} \mathrm{C}$ for dimethyl(diethyldithiocarbamato- $\kappa^{2}-S, S^{\prime}$ )gold(III) (B) (Scheme 1), which manifested in upper process temperatures being limited to $120^{\circ} \mathrm{C}$ and $180{ }^{\circ} \mathrm{C}$, respectively. We hypothesize that milder co-reagents than plasma or ozone could be used if higher deposition temperatures could be accessed, therefore requiring precursors with higher thermal stability. 


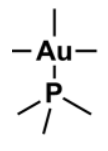

A

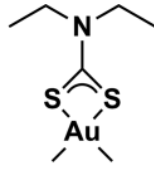

B
Scheme 1. Two previously reported precursors for gold ALD.

This work reports a study of a family of potential gold(I) vapor deposition precursors based on a framework with interchangeable coordinative and anionic ligands to allow a systematic structure-function understanding not only of the steric and electronic effects of these ligands, but also of their cooperative effects on the volatility and thermal stability of the compound.

Alkylgold(I) phosphine compounds are known to decompose through a bimolecular reductive elimination pathway (Scheme 2). Trimethylphosphine methylgold(I) (1a) is reported to be stable as a neat liquid until $150{ }^{\circ} \mathrm{C}$, at which point dissociation of trimethylphosphine occurs followed by bimolecular reductive elimination of ethane gas. ${ }^{[12]}$ However, on active metal surfaces this decomposition is known to occur as low as room temperature: the $\mathrm{Au}-\mathrm{PMe}_{3}$ bond dissociates on the surface, allowing bimolecular reductive elimination to take place. ${ }^{[13,14]}$

Given this, we focused on three complementary synthetic strategies to increase the thermal stability of $\mathrm{Au}(\mathrm{l})$ complexes. First, increasing the steric bulk of the anionic ligand should hinder the bimolecular reductive elimination pathway by preventing the association of adjacent surface-bound $\mathrm{Au}(\mathrm{I})$ species. Second, since the rate-limiting step of this reaction is dissociation of the coordinative phosphine ligand, a more electronwithdrawing anionic ligand should make the $\mathrm{Au}(\mathrm{I})$ center more acidic, thus strengthening the bond of the coordinative ligand. Lastly, using coordinative ligands of other known thermally stable $\mathrm{Au}(\mathrm{I})$ complexes may yield novel and useful ligand combinations. Thus, we envisioned a family of compounds that would allow us to discover which factors conferred the most thermal stability to organogold(I) compounds (Scheme 3).

Starting from the known methylgold(I) CVD precursor 1a, substituting trimethylsilylmethyl $\left[\mathrm{CH}_{2}\left(\mathrm{SiMe}_{3}\right)\right]$ and pentafluorophenyl $\left(\mathrm{C}_{6} \mathrm{~F}_{5}\right)$ ligands should impart a stepwise increase in the overall thermal stability of the compound. $\mathrm{CH}_{2}\left(\mathrm{SiMe}_{3}\right)$ is sterically bulkier than $\mathrm{Me}$ and is known to stabilize $\mathrm{Au}(\mathrm{l})$ species more so than non-silylated ligands. ${ }^{[15,16]}$ Both factors increase the thermal stability of transition metal complexes bearing this ligand, and have been used previously for manganese ALD precursor design. ${ }^{[17]}$ The $C_{6} F_{5}$ is much more $\sigma$-electron withdrawing due to perfluorination, which should result coordinative ligands forming a stronger bond to the gold center and increase the activation energy required for decomposition via bimolecular reductive coupling. Some $\mathrm{C}_{6} \mathrm{~F}_{5}$ complexes of gold with and

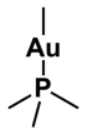

$1 \mathrm{a}$<smiles>C[Si](C)(C)C[GeH2][Si](C)(C)C</smiles>

2a<smiles>CP(C)(C)=[GeH]c1c(F)c(F)c(F)c(F)c1F</smiles>

$3 a$<smiles>C[Al]C[P+](C)(C)C</smiles>

$1 \mathrm{~b}$<smiles>C[Si](C)(C)C[Ge](C)(C)C[P+](C)(C)C</smiles>

$2 \mathbf{b}$<smiles>C[Al](C)(C[P+](C)(C)C)C(F)(F)F</smiles>

3b<smiles>C[Al]C([C+](C)C)[P+](C)(C)C</smiles>

1c<smiles>CC1CN(C(C)(C)C)CCN1C(C)(C)C</smiles>

1d
Scheme 3. Family of $\mathrm{Au}(\mathrm{I})$ compounds considered in this study.

without phosphine coordinative ligands have previously been shown to have high thermal stability, but have not been used for CVD or ALD. ${ }^{[18,19]}$

Phosphines are strongly binding coordinative ligands for organogold(I) compounds. Their chemistry is well known and predictable, the gold(I) compounds are stable to air and moisture, and they are generally quite volatile. We chose trimethylphosphine $\left(\mathrm{PMe}_{3}\right)$ as one of four neutral coordinative ligands (1a, $\mathbf{2 a}, \mathbf{3 a}$ ) due to its low molecular weight, ease of use in synthesis, and good $\sigma$-donation capabilities.

Schmidbaur and Franke reported "remarkably stable" organometallic gold(I) complexes bearing trimethylmethylene phosphorane (ylide) and trimethyl(trimethylsilylmethylene) phosphorane (TMS-ylide) phosphonium ylides as neutral coordinative ligands. ${ }^{[20]}$ These phosphonium ylides readily displace $\mathrm{PMe}_{3}$ from $\mathbf{1 a}$ and $\mathbf{2 a}$ giving $\mathbf{1} \mathbf{b}$ and $\mathbf{1} \mathbf{c}$, and $\mathbf{2} \mathbf{b}$ and $\mathbf{2 c}$ which were reported to be more thermally stable than the parent $\mathrm{PMe}_{3}$ complexes (decomposing above $150{ }^{\circ} \mathrm{C}$ in the case of $\mathbf{1 b}$ ). Since phosphonium ylide compounds of $\mathrm{Au}(\mathrm{I})$ have to the best of our knowledge not yet been tested for vapor deposition applications, and their volatilities have not been assessed, we included them and their $\mathrm{C}_{6} \mathrm{~F}_{5}$ analogues in this study.

$\mathrm{N}$-Heterocyclic carbenes (NHCs) have been successfully used in the design of ALD precursors for copper metal, a CVD precursor for gold metal, and an ALD precursor for silver metal. ${ }^{[21-24]}$ The compound $N, N^{\prime}$-di-tert-butylimidazolidin-2-ylidene ${ }^{[25]}$

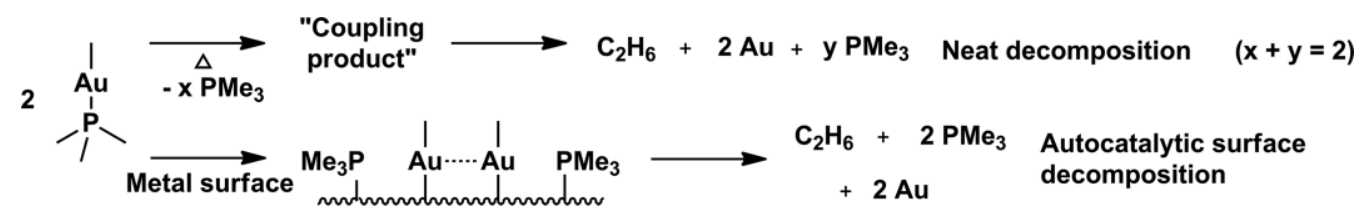

Scheme 2. Decomposition pathways for $\left(\mathrm{PMe}_{3}\right) \mathrm{AuMe}$ as a neat liquid and in the presence of an active metal surface. 
(NHC) is a monomeric, thermally stable, and sterically bulky saturated NHC with better $\sigma$-donor and $\pi$-acceptor properties than the more common imidazol-2-ylidene ligand class. This NHC should enhance the thermal stability of organogold(I) compounds due to its strong electron donating ability as well as its ability to sterically protect the $\mathrm{Au}(\mathrm{I})$ center.

\section{Results and Discussion}

\section{Synthesis and Characterization}

In literature examples of alkylgold(I) compounds, the desired species is often synthesized by salt metathesis from the corresponding gold(I) halide. However, given the propensity of phosphonium ylide- and NHC-gold(I) halides to form salts of the type $\left[\mathrm{Au}(\mathrm{L})_{2}\right]^{+}\left[\mathrm{AuX} \mathrm{X}_{2}\right]^{-[26,27]}$ and to reduce the required number of compounds for this study, we opted for a divergent synthetic strategy where the phosphonium ylide and NHC compounds would be synthesized from their respective parent alkylgold(I) phosphine complexes (Scheme 4).
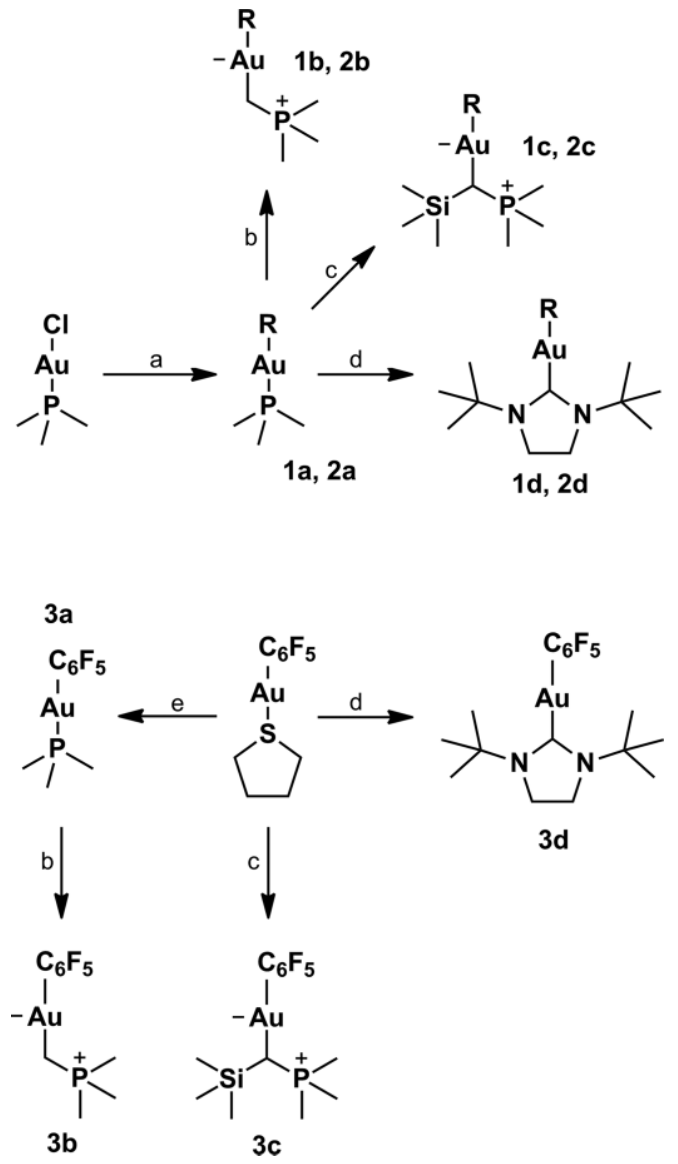

Scheme 4. Synthesis of all compounds. Reagents: a, MeLi (1a, $77 \%)$, $\left(\mathrm{SiMe}_{3}\right) \mathrm{CH}_{2} \mathrm{Li}(\mathbf{2 a}, 85 \%) ; \mathbf{b}, \mathrm{CH}_{2} \mathrm{PMe}_{3}$ (1) b, $\left.87 \%\right)$, (2b, $\left.82 \%\right),(3 \mathbf{b}, 65 \%) ; \mathbf{c}$, $\mathrm{CH}\left(\mathrm{PMe}_{3}\right)\left(\mathrm{SiMe}_{3}\right)(\mathbf{1 c}, 84 \%),(2 \mathrm{c}, 56 \%),(3 \mathbf{c}, 51 \%) ; \mathbf{d}, N_{,} N^{\prime}$-di-tert-butylimidazolidin-2-ylidene (1d, 94 \%), (2d, 87 \%), (3d, $89 \%$ ), e, $\mathrm{PMe}_{3}(3 \mathbf{a}, 94 \%)$.

The ligand exchange reaction produced volatile $\mathrm{PMe}_{3}$ and no other by-products which allowed for facile workup of these reactions. As detailed in the experimental section, an excess of the desired ligand was often used in order to completely con- sume the starting gold(I) phosphines which are difficult to remove by recrystallization or sublimation. Synthesis of $\mathbf{3} \mathbf{b}$ was initially attempted from the known compound (THT)AuC ${ }_{6} F_{5}$ since this saved one step in its synthesis [bypassing $\left(\mathrm{PMe}_{3}\right) \mathrm{AuC}_{6} \mathrm{~F}_{5}$. Unfortunately, this reaction produced a mixture of $\mathrm{PMe}_{3}{ }^{-}$, phosphonium ylide-, and $\mathrm{C}_{6} \mathrm{~F}_{5}$-containing compounds. However, when we attempted the same exchange reaction with $\mathbf{3 a}$ instead of (THT)AuC ${ }_{6} \mathrm{~F}_{5}, \mathbf{3} \mathbf{b}$ and $\mathbf{3 c}$ were produced as the majority products and were isolated by recrystallization. Compound $\mathbf{3 d}$ could be synthesized successfully from both (THT)AuC ${ }_{6} \mathrm{~F}_{5}$ and $3 \mathrm{a}$ by ligand exchange, but we deem the former procedure superior due to a reduction in synthetic steps.

We observed during workup that the ylide-containing complexes $\mathbf{1 b}$ and 1c decomposed upon attempted sublimation, and so we chose to purify phosphonium ylide species exclusively by recrystallization. All $\mathrm{PMe}_{3}$ and $\mathrm{NHC}$ complexes were purified by sublimation (or by distillation for for $\mathbf{2 a}$ ).

All compounds were characterized by ${ }^{1} \mathrm{H}-,{ }^{31} \mathrm{P}-,{ }^{19} \mathrm{~F}-$, and ${ }^{13} \mathrm{C}-\mathrm{NMR}$ spectroscopy, and were matched to literature reports where appropriate $\left(\mathbf{1} \mathbf{a},{ }^{[28]} \mathbf{1} \mathbf{b},{ }^{[29]} \mathbf{1} \mathbf{c}^{[30]} \mathbf{2} \mathbf{a},{ }^{[30]} \mathbf{2} \mathbf{b}_{,}{ }^{[30]} \mathbf{2} \mathbf{c}^{[26]} \mathbf{3} \mathbf{a}^{[31]}\right.$ are known, compounds $\mathbf{1 d}, \mathbf{2} \mathbf{d}, \mathbf{3 b}, \mathbf{3 c}, \mathbf{3 d}$ are novel). Our analysis of $3 a$ differed slightly by ${ }^{31}$ P-NMR analysis where the literature gives a chemical shift of 3.28 ppm and we instead observed the resonance at $-5.00 \mathrm{ppm}$ after purifying the compound by vacuum sublimation. The NHC compounds $\mathbf{1 d}, \mathbf{2 d}$, and $\mathbf{3 d}$ display characteristic NHC carbon resonances at 221.74, 219.94, and $211.05 \mathrm{ppm}$ in the ${ }^{13} \mathrm{C}-\mathrm{NMR}$ spectra which are similar to the free NHC (218.7 ppm). ${ }^{[32]}$ The compounds $\mathbf{3 b}$ and $\mathbf{3 c}$ were characterized by their ${ }^{31} \mathrm{P}-\mathrm{NMR}$ resonances which were observed at 26.50 and 23.65 ppm respectively, whose chemical shifts are very similar to $\mathbf{1} \mathbf{b}$ and $\mathbf{1} \mathbf{c}$, and $\mathbf{2} \mathbf{b}$ and $\mathbf{2} \mathbf{c}$. The $\mathrm{CH}\left(\mathrm{SiMe}_{3}\right) \mathrm{PMe}_{3}$ resonances $(\mathbf{1} \mathbf{c}, \mathbf{2 c}, \mathbf{3 c}$ ) were shielded by the increased electron density from the $\mathrm{SiMe}_{3}$ group compared to the non-substituted ylide compounds. Compounds $\mathbf{3 a}, \mathbf{2 b}, \mathbf{2 c}$, and $\mathbf{2 d}$ could not be differentiated from ionic salts of the type $\left[\mathrm{Au}(\mathrm{L})_{2}\right]^{+}\left[\mathrm{AuX}_{2}\right]^{-}$using NMR spectroscopy alone if the sample contains only one species, so the following X-ray crystallographic analyses served to confirm their neutral molecular arrangement.

\section{Crystallography}

Volatility is arguably the most important property of an ALD precursor as it sets the lower limit of useable process temperatures. It is primarily dictated by intermolecular forces and, to a lesser extent, by the molecular weight of the compound. Since a compound's volatility can be readily determined by TGA, we wanted to understand which intermolecular interactions most affect volatility. Single crystal X-ray crystallography was used to determine the solid-state packing of $\mathbf{1} \mathbf{c}$ and $\mathbf{1} \mathbf{d}, \mathbf{2} \mathbf{b}$ and $\mathbf{2} \mathbf{d}$, and 3a, 3b, 3c, and 3d (Figure 1). Selected bond lengths, angles, and other data are displayed for comparison in Table 1.

Compound 1c, like its TMS-ylide derivative $\mathbf{3 c}$, crystallizes as a 1:1 mixture of $R$ and $S$ enantiomers at the chiral ylidic carbon center coordinated to $\mathrm{Au}$. The $\mathrm{P}-\mathrm{C}_{\text {ylide }}$ bond length is shorter than the mean P-Me bond length [1.742(3) $\AA$ vs. 1.793(9) $\AA$ 

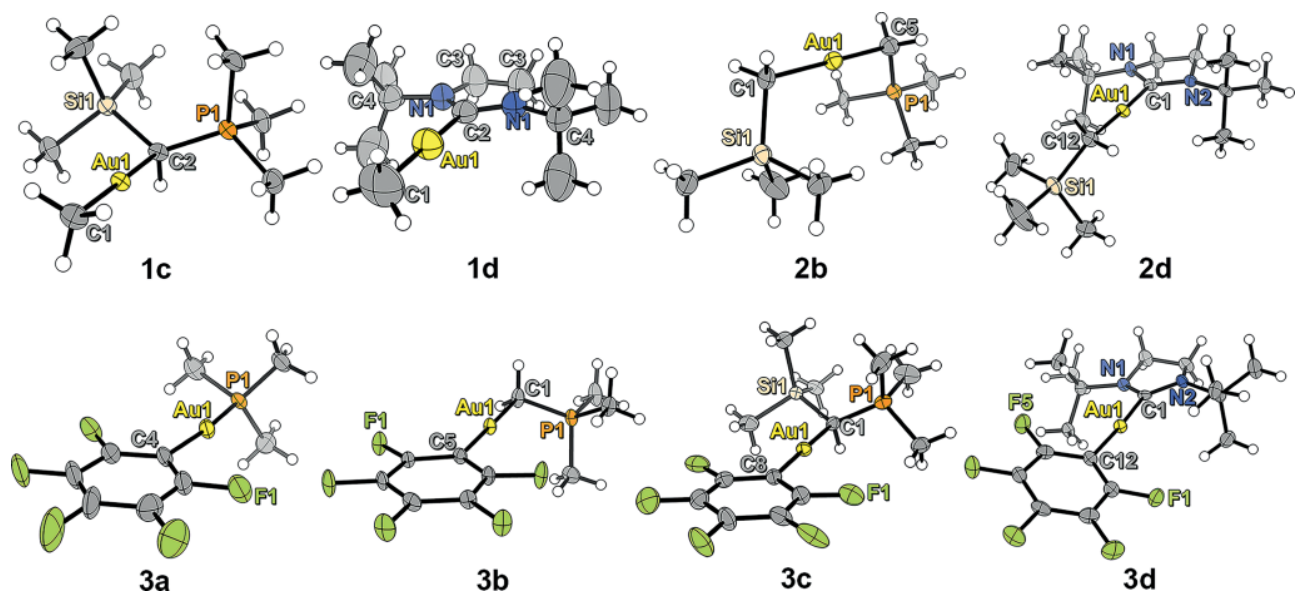

Figure 1. Solid-state structures of $\mathbf{1} \mathbf{c}, \mathbf{1} \mathbf{d}, \mathbf{2} \mathbf{b}, \mathbf{2} \mathbf{d}, \mathbf{3} \mathbf{a}, \mathbf{3} \mathbf{b}, \mathbf{3} \mathbf{c}$, and $\mathbf{3 d}$. In the cases of $\mathbf{1 c}$ and $\mathbf{3} \mathbf{c}$ only the $S$ enantiomers are shown. Ellipsoids are drawn at $50 \%$ probability in all diagrams.

Table 1. Selected bond lengths and angles for the analyzed compounds.

\begin{tabular}{|c|c|c|c|c|c|c|c|c|}
\hline & $\mathrm{R}^{-}$ & L & $\begin{array}{l}\mathrm{Au}-\mathrm{R} \\
{\left[{ }^{\circ}\right]}\end{array}$ & $\begin{array}{l}\mathrm{Au}-\mathrm{L} \\
\left.{ }^{0}\right]\end{array}$ & $\begin{array}{l}\text { P-Cylide } \\
{\left[^{\circ}\right]}\end{array}$ & $\begin{array}{l}\text { Average P-Me } \\
{[\AA ̊]}\end{array}$ & $\begin{array}{l}\mathrm{NCN} \text { bond angle } \\
{\left[^{\circ}\right]}\end{array}$ & $\begin{array}{l}\text { R-Au-L } \\
{\left[^{\circ}\right]}\end{array}$ \\
\hline $1 c$ & $\mathrm{Me}$ & TMS-ylide & $2.057(3)$ & $2.136(3)$ & $1.742(3)$ & $1.793(9)$ & - & $178.1(1)$ \\
\hline 1d & $\mathrm{Me}$ & $\mathrm{NHC}$ & $2.069(8)$ & $2.055(6)$ & - & - & $108.5(5)$ & 180 \\
\hline $2 b$ & $\mathrm{CH}_{2}\left(\mathrm{SiMe}_{3}\right)$ & Ylide & $2.10(1)$ & $2.09(1)$ & $1.77(1)$ & $1.80(4)$ & - & $178.5(3)$ \\
\hline $2 d$ & $\mathrm{CH}_{2}\left(\mathrm{SiMe}_{3}\right)$ & $\mathrm{NHC}$ & $2.059(7)$ & $2.045(7)$ & - & - & 108.5(6) & $178.1(3)$ \\
\hline $3 a$ & $\mathrm{C}_{6} \mathrm{~F}_{5}$ & $\mathrm{PMe}_{3}$ & $2.053(5)$ & $2.280(1)$ & - & - & - & $172.8(1)$ \\
\hline $\mathbf{3 b}$ & $\mathrm{C}_{6} \mathrm{~F}_{5}$ & Ylide & $2.046(3)$ & 2.081() & $1.763(3)$ & $1.789(10)$ & - & $177.9(1)$ \\
\hline $3 c$ & $\mathrm{C}_{6} \mathrm{~F}_{5}$ & TMS-ylide & $2.041(3)$ & $2.104(3)$ & $1.759(3)$ & $1.789(11)$ & - & $178.4(1)$ \\
\hline 3d & $\mathrm{C}_{6} \mathrm{~F}_{5}$ & $\mathrm{NHC}$ & $2.039(4)$ & $2.031(4)$ & - & - & 109.4(3) & $176.7(1)$ \\
\hline
\end{tabular}

respectively], and the $\mathrm{P}-\mathrm{C}_{\text {ylide }}-\mathrm{Si}$ angle $\left[121.6(2)^{\circ}\right]$ is much larger than expected for a tetrahedral geometry. These factors indicate that the bonding of this ligand lies somewhere between its two extreme canonical structures (Scheme 5). Steric repulsion between the $\mathrm{PMe}_{3}$ and $\mathrm{SiMe}_{3}$ groups of the ylide may influence the large angle and therefore hinder the $\sigma$-donating ability of this ligand. Likewise, compound $\mathbf{3 c}$ displays a $\mathrm{P}-\mathrm{C}_{\text {ylide }}$ bond length of 1.759(3) $\AA$, an average P-Me bond length of 1.798(11) $\AA$, and a P-C $\mathrm{C}_{\text {ylide }}-\mathrm{Si}$ bond angle of $121.7(2)^{\circ}$, all of which implies a significant ylene character. More ylene character translated to higher volatility in TMS-ylide compounds (vide infra).<smiles>C[AsH2]=C[AsH2]</smiles><smiles>[CH][CH]</smiles><smiles>C[AsH2-]C(C)C</smiles>
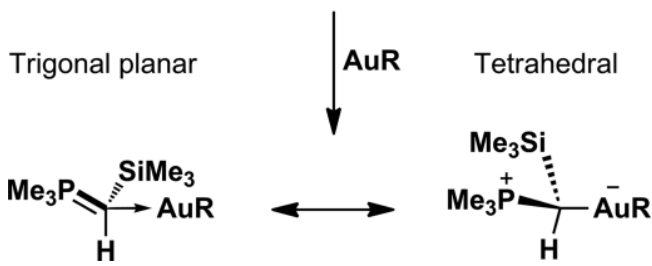

Scheme 5. Resonance structures depicting the extreme canonical resonance structures and ligand geometries of compounds 1, 2, 3c.

In the structure of $\mathbf{2} \mathbf{b}$, the acceptance of electron density from the ylidic carbon by the Au center is much more pronounced as shown by the shorter $\mathrm{Au}-\mathrm{L}$ bond. The $\mathrm{P}-\mathrm{C}_{\text {ylide }}$ bond length in $\mathbf{2} \mathbf{b}$ is elongated compared to that of trimethylmethylene phosphorane [1.77(1) $\AA$ and 1.640(6) Å respectively] ${ }^{[33]}$ and the $P-C_{\text {ylide }}$ bond length is not significantly different from the mean P-Me bond length [1.77(1) $\AA$ vs. 1.80(4) $\AA$, respectively]. This is similarly observed in $\mathbf{3} \mathbf{b}$ and distinguishes $\mathbf{2} \mathbf{b}$ and $\mathbf{3} \mathbf{b}$ from $1 c$ and $3 c$ as being primarily ylidic in nature, which led to a suppression of volatility.

When comparing R-Au bond lengths, the $\mathrm{C}_{6} \mathrm{~F}_{5}$ compounds all exhibit shorter bonds than other compounds with the same coordinative ligand: $\mathbf{1 d} \approx \mathbf{2} \mathbf{d}>\mathbf{3 d}, \mathbf{1 c}>\mathbf{3 c}$, and $\mathbf{2 b}>\mathbf{3 b}$. This is primarily due to the covalent radius of the $\mathrm{sp}^{2}$-hybridized carbon in the $\mathrm{C}_{6} \mathrm{~F}_{5}$ ring being slightly smaller than that of the $\mathrm{sp}^{3}$-hybridized carbon atoms in the $\mathrm{Me}$ and $\mathrm{CH}_{2}\left(\mathrm{SiMe}_{3}\right)$ ligands. Furthermore, $\mathrm{C}_{6} \mathrm{~F}_{5}$ complexes $\mathbf{3} \mathbf{a}, \mathbf{3 b} \mathbf{3} \mathbf{3} \mathbf{c}$, and $\mathbf{3 d}$ display shorter $\mathrm{Au}-\mathrm{L}$ bond lengths than their aliphatic derivatives, which is due to the strong electron-withdrawing ability of the $C_{6} F_{5}$ ligand. From these results, it appeared that $\mathrm{C}_{6} \mathrm{~F}_{5}$ was an especially good ligand for improving the thermal stability of $\mathrm{Au}(\mathrm{l})$ compounds for two reasons. Firstly, the rate-limiting step for decomposition must proceed through cleavage of a stronger coordinative bond, and secondly because the final reductive elimination step must occur between two strongly bound, electron-deficient carbon atoms.

In the solid state, each molecule of $\mathbf{3 a}$ is associated to its neighbors by polymeric $\mathrm{Au}-\mathrm{Au}$ aurophilic interactions [Au-Au distance 3.3703(6) $\AA$ ]. This was the only compound structurally characterized in this work that displayed aurophilicity (Figure 2). 
This is an intermediate-to-long range aurophilic interaction, ${ }^{[34]}$ and is likely only observed for $3 a$ because $\mathrm{PMe}_{3}$ is the least sterically ligand in this study. By comparison the previously reported $\mathrm{PPh}_{3}$ analogue does not display aurophilic interactions, but instead undergoes a $\pi$-stacking interaction between the $\mathrm{C}_{6} \mathrm{~F}_{5}$ ligands, possibly due to the steric bulk of the $\mathrm{PPh}_{3}$ ligand interfering with the $\mathrm{Au}-\mathrm{Au}$ interaction. ${ }^{[35]}$

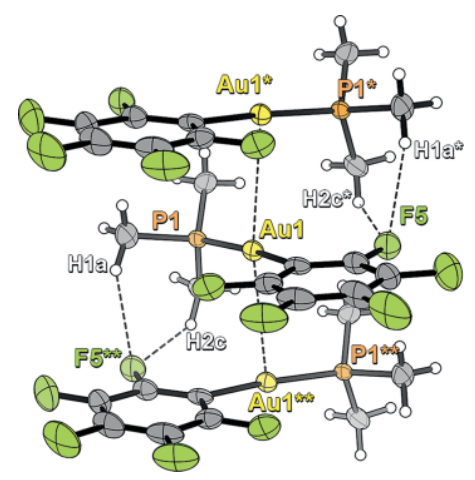

Figure 2. Extended structure of 3a showing the aurophilic polymer chain. Thermal ellipsoids are shown at $50 \%$ probability. Selected intermolecular interaction distances [Å]: $\mathrm{Au}(1)-\mathrm{Au}(2) \quad 3.3703(6), \mathrm{H}(1 \mathrm{a})-\mathrm{F}\left(5^{* *}\right)$ 2.492, $\mathrm{H}(2 \mathrm{c})-$ $\mathrm{F}\left(5^{* *}\right) 2.527$.

Some studies have previously linked the volatility of $\mathrm{Au}(\mathrm{I})$ compounds to solid-state aurophilic interactions. ${ }^{[36,37]}$ However a recent computational paper by Mata et al. ${ }^{[38]}$ cautioned that aurophilic interactions aren't necessarily the dominant intermolecular force holding the molecules together, and Au-ligand interactions or inter-ligand interactions dictate solid-state packing arrangements to a greater degree. Thus, we have attempted to describe the number and types of interactions that occur throughout the system which overall affect the compound's volatility.

In Figure 2 other in-chain intermolecular interactions are observed between the $\mathrm{PMe}_{3}$ ligands. Each phosphine engages in two $\mathrm{H}-\mathrm{F}$ interactions to an adjacent molecule $\left[\mathrm{H}(1 \mathrm{a})-\mathrm{F}\left(5^{* *}\right)\right.$ $\left.2.492 \AA, H(2 \mathrm{C})-F\left(5^{* *}\right) 2.527 \AA\right]$. These strong hydrogen bonding interactions translated to a suppression of the volatility of $\mathbf{3 a}$ compared to $\mathbf{1} \mathbf{a}$ and $\mathbf{2} \mathbf{a}$.

Compound $\mathbf{3} \mathbf{b}$ is involved in a $\pi$-stacking interaction with a centroid to centroid distance of $3.497 \AA$. These $\pi$-stacked dimers are involved in secondary interactions with other $\pi$ stacked dimers along the crystallographic $b \times(a+c)$ plane through a set of $\mathrm{F}-\mathrm{F}, \mathrm{C}-\mathrm{F}$, and $\mathrm{C}-\mathrm{C}$ interactions (Figure 3 ). The extensive intermolecular network formed by $\mathbf{3} \mathbf{b}$ shows that the addition of $\mathrm{C}_{6} \mathrm{~F}_{5}$ group introduces many more intermolecular interactions when coupled with a small ligand like $\mathrm{PMe}_{3}$ or $\mathrm{CH}_{2} \mathrm{PMe}_{3}$ than with larger ligands like $\mathrm{CH}_{2} \mathrm{PPh}_{3}$ and resulted in a reduced volatility of this compound. This compound displayed the largest number of intermolecular interactions of the family (Table 2).

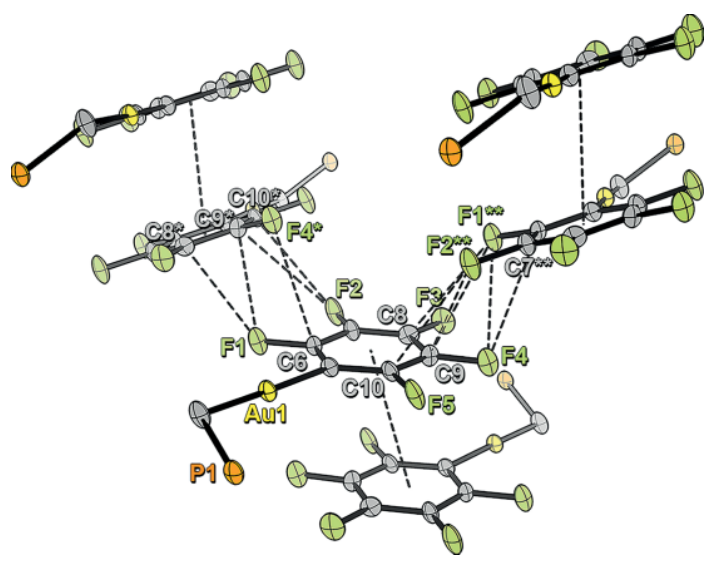

Figure 3. $\mathrm{C}_{6} \mathrm{~F}_{5}-\mathrm{C}_{6} \mathrm{~F}_{5}$ intermolecular interactions in $\mathbf{3 b}$. The diagram displays pairs that occur along the crystallographic $b \times(a+c)$ plane. Methyl moieties of the ylide and hydrogen atoms have been omitted for clarity. Thermal ellipsoids are shown at $50 \%$ probability. Selected intermolecular interaction distances $[\AA]$ : centroid-to-centroid 3.497, $F\left(2^{* *}\right)-C(10) 3.210(3), F\left(2^{* *}\right)-C(9)$ $3.166(3), C\left(7^{* *}\right)-F(4) 3.231(6), F\left(1^{* *}\right)-F(4) 2.928(2), F\left(1^{* *}\right)-C(9) 3.127(3), F\left(1^{* *}\right)-$ C(8) 3.145(3).

Compound $3 \mathrm{c}$ does not $\pi$-stack in the solid state, instead the $\mathrm{C}_{6} \mathrm{~F}_{5}$ ligands interact to form chains via $(\mathrm{C}-\mathrm{F})-\mathrm{F}$ interactions, although there are considerably fewer than observed in $\mathbf{3 b}$ (Fig-

Table 2. Important metrics obtained from TGA and DSC experiments.

\begin{tabular}{|c|c|c|c|c|c|c|}
\hline & $\begin{array}{l}\mathrm{T}_{\mathrm{V}} \\
{\left[{ }^{\circ} \mathrm{C}\right]}\end{array}$ & $\begin{array}{l}\mathrm{T}_{\mathrm{D}} \\
{\left[{ }^{\circ} \mathrm{C}\right]}\end{array}$ & $\begin{array}{l}\text { Useful } \\
\text { temperature } \\
\text { range }\left[{ }^{\circ} \mathrm{C}\right]^{[\mathrm{a}]}\end{array}$ & $\begin{array}{l}\text { Residual } \\
\text { mass } \\
{[\%]}\end{array}$ & $\begin{array}{l}\text { Fractional } \\
\text { Gold } \\
\text { remaining [\%] }\end{array}$ & $\begin{array}{l}\text { Figure } \\
\text { of Merit } \\
(\sigma)^{[\mathrm{b}]}\end{array}$ \\
\hline $1 a$ & 68 & 130 & 62.5 & 34.3 & 50.2 & 31.1 \\
\hline $1 b$ & - & 107 & - & 22.9 & 35.1 & - \\
\hline $1 c$ & - & 129 & - & 36.9 & 70.1 & - \\
\hline $1 d$ & 157 & 189 & 32.5 & 34.9 & 69.9 & 9.8 \\
\hline $2 a$ & 87 & 146 & 59.1 & 0.8 & 1.5 & 58.2 \\
\hline $2 b$ & - & 152 & - & 2.5 & 4.8 & - \\
\hline $2 c$ & 134 & 118 & -16.8 & 5.9 & 13.4 & -14.6 \\
\hline $2 d$ & 150 & 184 & 33.1 & 11.9 & 28.2 & 23.8 \\
\hline $3 a$ & 152 & 185 & 33.1 & 1.1 & 2.5 & 32.3 \\
\hline $3 b$ & - & 220 & - & 41.3 & 95.2 & - \\
\hline $3 c$ & 148 & 253 & 104.7 & 33.3 & 88.8 & 11.7 \\
\hline $3 d$ & 200 & 300 & 99.7 & 1.6 & 4.4 & 95.3 \\
\hline
\end{tabular}

[a] Difference between $T_{\mathrm{V}}$ and $T_{\mathrm{D}}$. [b] See Equation 1. Dashes indicate that insufficient mass loss data could be obtained before the measured self-decomposition temperature of that compound. 
ure 4). This demonstrates the ability of sterically bulky coordinative ligands to suppress intermolecular interactions in $\mathrm{C}_{6} \mathrm{~F}_{5}-\mathrm{Au}$ complexes.

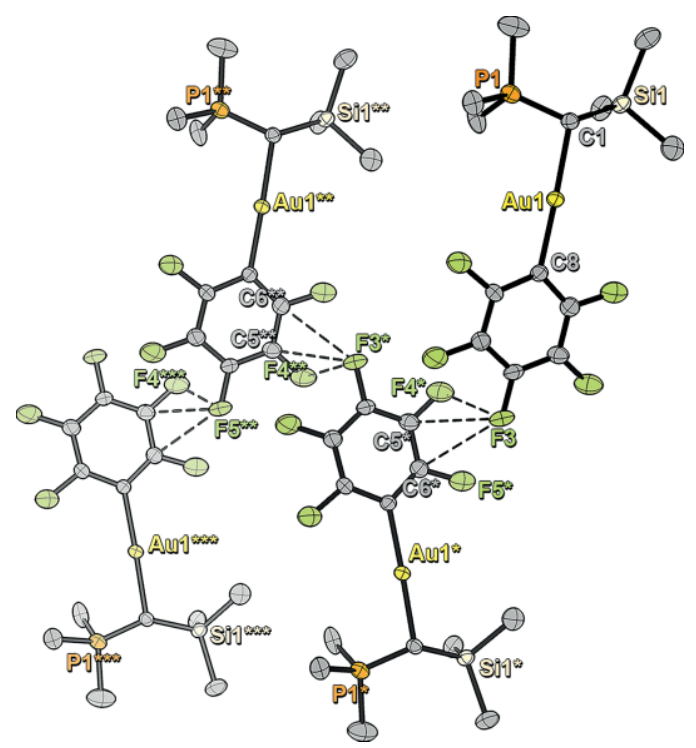

Figure 4. $\mathrm{C}_{6} \mathrm{~F}_{5}-\mathrm{C}_{6} \mathrm{~F}_{5}$ intermolecular interactions in $\mathbf{3 c}$. Hydrogen atoms have been omitted for clarity and thermal ellipsoids have been drawn at the $50 \%$ probability level. The top two molecules are the $(S)$ enantiomer while the bottom two are the $(R)$ enantiomer. Selected intermolecular interaction distances $[\AA ̊]$ ]: $F(3)-F\left(4^{*}\right) 2.912(3), F(3)-C\left(2^{*}\right) 3.151(4), F(3)-C\left(3^{*}\right) 3.214(3)$.

Compound 3d displays fewer overall intermolecular contacts than other $\mathrm{C}_{6} \mathrm{~F}_{5}$ compounds which we attribute to the large steric bulk of the $\mathrm{NHC}$. The $\mathrm{C}_{6} \mathrm{~F}_{5}$ inter-ligand interactions are suppressed compared to $\mathbf{3 C}$, where here only a single pair of $(C-C)-F p-\pi$ interactions (Figure 5 ) are allowed.

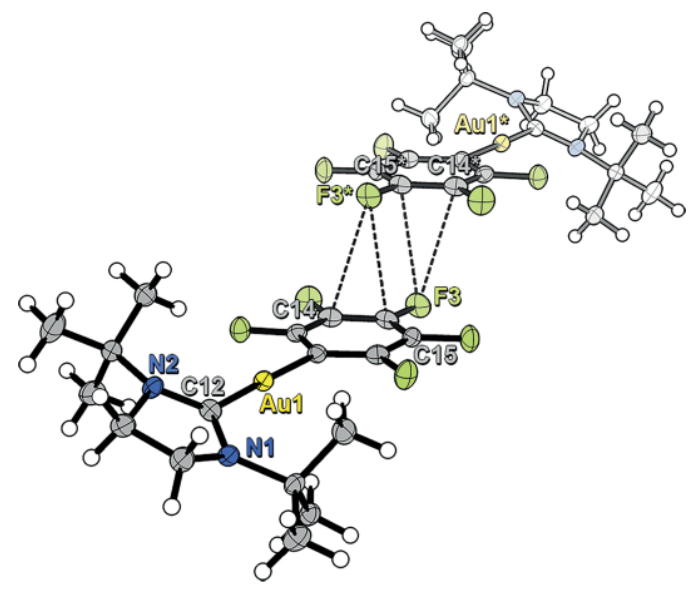

Figure 5. $\mathrm{C}_{6} \mathrm{~F}_{5}-\mathrm{C}_{6} \mathrm{~F}_{5}$ intermolecular interactions in $\mathbf{3 d}$. Thermal ellipsoids have been drawn at the $50 \%$ probability level. Selected intermolecular interaction distances $[\AA]$ : $C(14)-F\left(3^{*}\right)$ 3.095(4), $C(15)-F\left(3^{*}\right) 3.043(4)$.

Complexes bearing $\mathrm{Me}$ (1c and $\mathbf{1 d}$ ) or $\mathrm{CH}_{2}\left(\mathrm{SiMe}_{3}\right)$ ( $\mathbf{2 b}$ and 2d) ligands display no intermolecular contacts. In contrast, $\mathrm{C}_{6} \mathrm{~F}_{5}$ complexes (3a, 3b, 3c, and $\mathbf{3 d}$ ) display far more intermolecular interactions in the solid state, and we surmise that this is the main reason for their decreased volatility (see below).

\section{Thermolysis}

For a compound to be a potential ALD candidate, high thermal stability and volatility are required. Thermogravimetric analysis (TGA) of a thermally stable and volatile compound shows an exponential mass loss with constantly increasing temperature as described by the Clausius-Clapeyron equation. Thermally stable compounds also leave a very low final residual mass indicative of evaporation without decomposition to non-volatile byproducts. The vapor pressure of a compound can be calculated from TGA data using a previously developed method (Figures S38-S45). ${ }^{[39]}$ The temperature at which a compound achieves a vapor pressure of 1 Torr (i.e., its 1 Torr temperature, $T \mathbf{V}$ ) may be used as a benchmark for comparison since commercial ALD reactors typically operate close to this pressure. While TGA can also give clues about decomposition of the sample compound, differential scanning calorimetry (DSC) is better at analyzing the onset of decomposition of these compounds. By graphically determining the point at which the decomposition exotherm has reached $5 \%$ of it's maximum height, we obtained a decomposition temperature (TD) for the compound in question (Figures S46-S57). The results of these analyses are tabulated below (Table 2).

In the TGA ramp experiments of $\mathbf{1 a - d}$ (Figure 6), none of the compounds were thermally stable enough to evaporate completely, however in each case some sample did evaporate intact which we can infer from the percent atomic mass of $\mathrm{Au}$ in the compound compared to the final residual mass of the experiment (see inset). All sample pans were left with a visibly golden coating after the experiments.

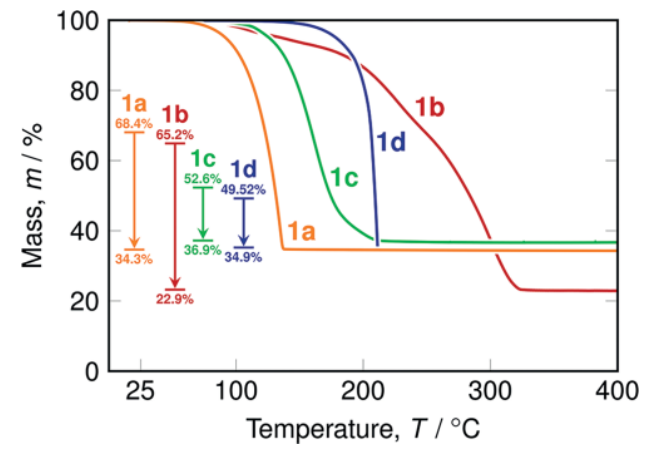

Figure 6. TGA of $\mathbf{1 a}-\mathbf{d}$ at a ramp rate of $10{ }^{\circ} \mathrm{C} / \mathrm{min}$. The inset vertical ranges show the \% mass of $\mathrm{Au}$ in each compound (top line) and the final residual mass of the respective analysis (bottom line).

In the case of $\mathbf{1 a}$ it is interesting that such a high residual mass is observed, given that the self-decomposition point $\left(130{ }^{\circ} \mathrm{C}\right)$ is close to the end of the mass loss curve. This can be explained by the known autocatalytic decomposition of alkylgold(I) phosphines that occurs as low as room temperature on $\mathrm{Cr}, \mathrm{Cu}$ and Au surfaces. ${ }^{[13]}$ Some decomposition likely occurs on the Pt surface of the pan at temperatures below the onset of self-decomposition results in an increased residual mass. This occurs more readily for the phosphine than for the NHC which implies a strong NHC-Au bond. No inflection is observed in the exponential mass loss curves of $\mathbf{1} \mathbf{a}$ and $\mathbf{1} \mathbf{d}$ suggesting that the decomposition products are gaseous (ethane, $\mathrm{PMe}_{3}, \mathrm{NHC}$ ) or 
non-volatile (metallic gold), and therefore their production does not affect the rate of mass loss of the sample.

In the case of compounds $\mathbf{1} \mathbf{b}$ and $\mathbf{1 c}$, concurrent evaporation and decomposition were observed by the presence of multiple inflection points in their respective mass loss curves. Here the products formed by thermolysis are semi-volatile or are themselves thermally unstable. This makes the by-products observable as changes to the mass loss rate, implying low-volatility organic molecules or other gold complexes are the primary decomposition products of $\mathbf{1} \mathbf{b}$ and $\mathbf{1} \mathbf{c}$.

The $\mathrm{CH}_{2}\left(\mathrm{SiMe}_{3}\right)$ gold(I) compounds $\mathbf{2 a}$ and $\mathbf{2} \mathbf{d}$ performed much better in TGA analyses (Figure 7) than $\mathbf{1 a}$ and $\mathbf{1 d}$. Compound $\mathbf{2 a}$ appears to evaporate very cleanly, the only indication of slight decomposition being the small residual mass of $0.8 \%$. Compound $\mathbf{2 d}$ evaporates with decomposition in a single step to $11.9 \%$.

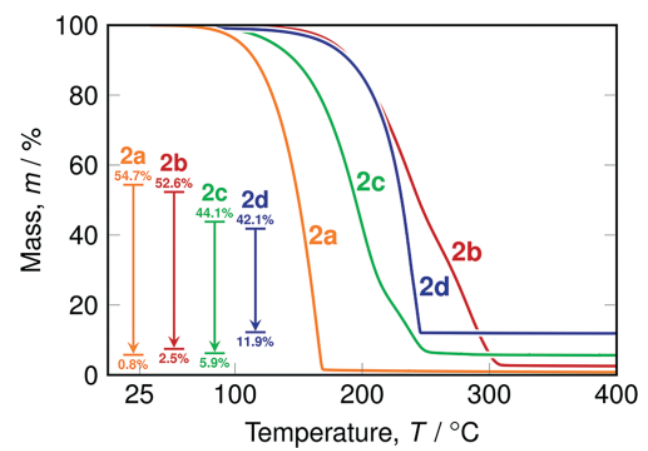

Figure 7. TGA ramp experiments of $\mathbf{2} \mathbf{a}-\mathbf{d}$ at a ramp rate of $10{ }^{\circ} \mathrm{C} / \mathrm{min}$. The inset vertical ranges show the $\%$ mass of $\mathrm{Au}$ in each compound (top line) and the final residual mass of the respective analysis (bottom line).

Compounds $\mathbf{2} \mathbf{b}$ and $\mathbf{2 c}$ undergo multiple decomposition events like $\mathbf{1 b}$ and $\mathbf{1} \mathbf{c}$. However, it is obvious that the $\mathrm{CH}_{2}\left(\mathrm{SiMe}_{3}\right)$ ligand improves thermal performance by TGA because the residual masses of $\mathbf{2} \mathbf{b}$ and $\mathbf{2} \mathbf{c}$ are much lower, meaning more of the gold has ultimately evaporated from the system.

The $\mathrm{C}_{6} \mathrm{~F}_{5}$ compounds $\mathbf{3} \mathbf{a}$ and $\mathbf{3} \mathbf{d}$ performed very well by TGA (Figure 8), each evaporating in a single step and leaving a very low residual mass (3a: $1.1 \%$; 3d: $1.6 \%$ ). Volatilization occurs at higher temperatures for these species, and $\mathbf{3} \mathbf{d}$ shows a marked improvement in its thermal stability compared to $\mathbf{1 d}$ and $\mathbf{2 d}$. Clearly $\mathrm{C}_{6} \mathrm{~F}_{5}$ imparts a strong stabilization to gold(I) and improves the thermal stability of the system, although at the expense of volatility.

Compounds $\mathbf{3} \mathbf{b}$ and $\mathbf{3} \mathbf{c}$ performed worse than their Me and $\mathrm{CH}_{2}\left(\mathrm{SiMe}_{3}\right)$ counterparts, decomposing extensively and leaving the highest gold residues of the family (> $85 \%$ ). The introduction of the $\mathrm{C}_{6} \mathrm{~F}_{5}$ ligand does improve thermal stability when compared with the aliphatic derivatives, but in the case of $\mathbf{3} \mathbf{b}$ and $\mathbf{3} \mathbf{c}$, the reduction in volatility is too great to result in a useful precursor.

Using the thermal data collected, we defined a figure of merit $(\sigma)$ to compare the viability of these compounds for use in vapor deposition processes [Equation (1)]. This figure of merit is made up of thermodynamic and kinetic terms that together describe the suitability of the vapor deposition precursor. Not

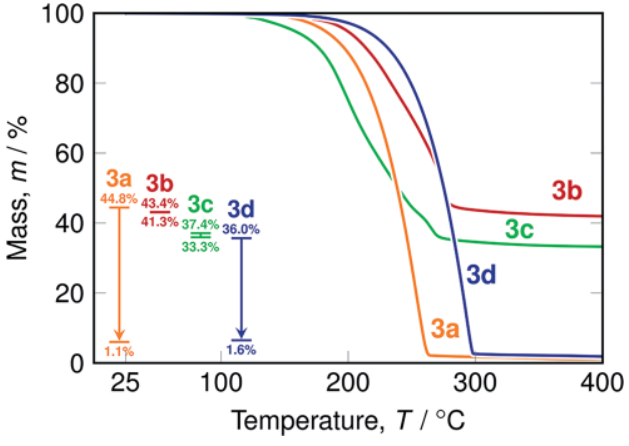

Figure 8. TGA ramp experiments of $\mathbf{3 a}-\mathbf{d}$ at a ramp rate of $10{ }^{\circ} \mathrm{C} / \mathrm{min}$. The inset vertical ranges show the $\%$ mass of $\mathrm{Au}$ in each compound (top line) and the final residual mass of the respective analysis (bottom line).

only does it include decomposition temperature and vapor pressure, but if two compounds that both undergo the same decomposition mechanism are compared, the one which resists decomposition longer will receive a higher figure of merit. This highlights that some of the compounds are more kinetically stable (e.g. 2a, 3a) than others (e.g. 1a). Particularly, 3a persists in the TGA experiment far past its onset of self-decomposition measured by DSC $\left(185^{\circ} \mathrm{C}\right)$. Thus, weighting the figure of merit by the residual mass demonstrates the importance of kinetic and thermodynamic stability of a potential precursor compound.

$\sigma=\left(T_{D}-T_{V}\right) \times\left(1-\frac{\% m_{\text {res }}}{196.97 / \mathrm{mw} \times 100 \%}\right)$

The calculated $\sigma$ values for the family of compounds are included in Table 2. Certain compounds (1 $\mathbf{1 b}, \mathbf{1} \mathbf{c}, \mathbf{2 b}, \mathbf{3 b}$ ) were not given a $\sigma$ value because insufficient mass loss data could be obtained before the TGA experiment reached the self-decomposition temperature (DSC) of the analyte in question. The merits of each compound in this family can be visualized using a "minefield" diagram (Figure 9). Since the delivery temperature of a precursor is an unavoidable consideration in process design, each circle is centered at the compound's respective $T_{\mathrm{V}}$.

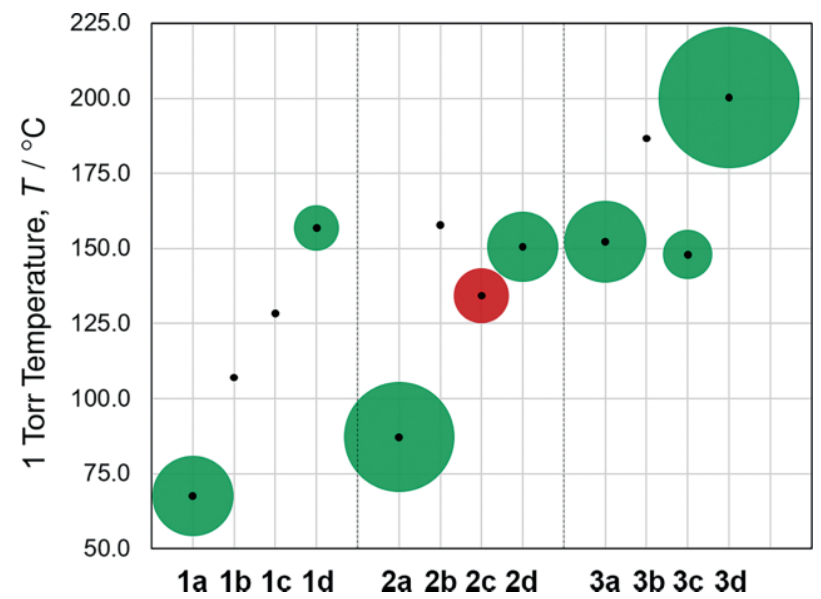

Figure 9. Figure of merit "minefield" plot. Green circles indicate a positive figure of merit while red circles indicate a negative figure of merit. The $\sigma$ value of each compound is shown as the radius of each circle in arbitrary units. 
Table 3. Calculated energies and measured decomposition temperatures of the three ligand dissociation cases for model compounds and synthesized compounds.

\begin{tabular}{|c|c|c|c|c|}
\hline Compound & $\begin{array}{l}\text { Dissociation of } \\
\text { coordinative ligand } \\
{[\mathrm{kJ} / \mathrm{mol}]}\end{array}$ & $\begin{array}{l}\text { Homolytic } \\
\text { cleavage } \\
{[\mathrm{kJ} / \mathrm{mol}]}\end{array}$ & $\begin{array}{l}\text { Heterolytic } \\
\text { cleavage } \\
{[\mathrm{kJ} / \mathrm{mol}]}\end{array}$ & $\begin{array}{l}T_{\mathrm{d}}{ }^{[\mathrm{a}]} \\
{\left[{ }^{\circ} \mathrm{C}\right]}\end{array}$ \\
\hline $\mathrm{CH}_{2}\left(\mathrm{SiMe}_{3}\right)-\mathrm{Au}-\mathrm{PH}_{3}\left(\mathbf{2} \mathbf{a}^{*}\right)$ & 119 & 293 & - & - \\
\hline $\mathrm{CH}_{2}\left(\mathrm{SiMe}_{3}\right)-\mathrm{Au}-\mathrm{PMe}_{3}(\mathbf{2 a})$ & 171 & - & - & 145 \\
\hline $\mathrm{CH}_{2}\left(\mathrm{SiMe}_{3}\right)-\mathrm{Au}-\mathrm{H}_{2} \mathrm{NHC}\left(\mathbf{2} \mathbf{d}^{*}\right)$ & 215 & 452 & - & - \\
\hline $\mathrm{CH}_{2}\left(\mathrm{SiMe}_{3}\right)-\mathrm{Au}-t \mathrm{BuNHC}(\mathbf{2 d})$ & 221 & - & - & 184 \\
\hline $\mathrm{C}_{6} \mathrm{~F}_{5}-\mathrm{Au}-\mathrm{PH}_{3}(3 \mathrm{a} *)$ & 153 & 422 & 727 & - \\
\hline $\mathrm{C}_{6} \mathrm{~F}_{5}-\mathrm{Au}-\mathrm{PMe}_{3}(\mathbf{3 a})$ & 212 & - & - & 185 \\
\hline $\mathrm{C}_{6} \mathrm{~F}_{5}-\mathrm{Au}-\mathrm{H}_{2} \mathrm{NHC}\left(\mathbf{3 d}^{*}\right)$ & 263 & 593 & 665 & - \\
\hline $\mathrm{C}_{6} \mathrm{~F}_{5}-\mathrm{Au}-t \mathrm{BuNHC}(\mathbf{3 d})$ & 277 & - & - & 300 \\
\hline
\end{tabular}

[a] Onset of self-decomposition as measured by DSC.

If delivery temperature is not an important requirement, then clearly compound $\mathbf{3 d}$ is the most promising precursor candidate for vapor deposition. It has a $T_{V}$ of $200{ }^{\circ} \mathrm{C}$ however, so if only lower delivery temperatures are desired $\mathbf{2 a}$ is likely the preferred candidate. These are two excellent candidates for the development of ALD processes that include gold, and they are currently under investigation in our group.

\section{DFT Study}

To better understand the reason behind the high figures of merit obtained for phosphine and NHC systems, we undertook a density functional theory (DFT) study of compounds $\mathbf{2 a}, \mathbf{2 d}$, $\mathbf{3 a}$, and $\mathbf{3 d}$. The calculations were first performed using model compounds $\mathbf{2} \mathbf{a}^{*}, \mathbf{2} \mathbf{d}^{*}, \mathbf{3} \mathbf{a}^{*}$, and $\mathbf{3} \mathbf{d}^{*}$ where the $\mathrm{PMe}_{3}$ and $\mathrm{NHC}$ ligands were replaced with proto analogues $\left[\mathrm{PH}_{3}\right.$ and $N_{1} N^{\prime}$-dihydroimidazolidin-2-ylidene $\left.\left(\mathrm{H}_{2}-\mathrm{NHC}\right)\right]$, to examine the energy required to break the $\mathrm{Au}-\mathrm{R}$ and $\mathrm{Au}-\mathrm{L}$ bonds. All calculations were carried out using the $\omega B 97 X-D$ functional ${ }^{[40,41]}$ and the iMCP-SR2 model core potentials and basis sets. ${ }^{[42]}$ Scalar-relativistic model core potentials are known to provide satisfactory description for heavy elements like Au. ${ }^{[43]}$ The dissociation energies of the $\mathrm{R}^{-}$and $\mathrm{L}$ ligand fragments were determined by calculating the difference in energy between the free ligand in question and the remaining $\mathrm{Au}-\mathrm{L}$ or $\mathrm{Au}-\mathrm{R}$ fragment. Three scenarios were considered: dissociation of the coordinative ligand, forming a neutral R-Au fragment and a neutral L fragment; homolytic cleavage of the $\mathrm{R}-\mathrm{Au}$ bond resulting in $\mathrm{R} \cdot$ and $\cdot \mathrm{Au}-\mathrm{L}$ fragments; and heterolytic cleavage of the R-Au bond resulting in $\mathrm{R}^{-}$and $+\mathrm{Au}-\mathrm{L}$ fragments (Table 3 ). Heterolytic cleavage was discounted after considering the results of $\mathbf{3} \mathbf{a}^{*}$ and $\mathbf{3} \mathbf{d}^{*}$, because it was consistently the highest energy case and was therefore unlikely to contribute to the first thermolysis events of the molecules. For $\mathbf{2} \mathbf{a}, \mathbf{2} \mathbf{d}, \mathbf{3} \mathbf{a}$, and $\mathbf{3} \mathbf{d}$, only dissociation of the neutral $L$ ligand was considered since it is known to be the primary decomposition pathway for alkylgold(I) compounds. It was also the lowest energy case, implying it was the largest contributor to thermal decomposition.

The model compounds $\mathbf{2} \mathbf{a}^{*}, \mathbf{2} \mathbf{d}^{*}, \mathbf{3} \mathbf{a}$, and $\mathbf{3} \mathbf{d}^{*}$ mirrored the general trends of thermal stability that were observed experimentally. The energy required for homolytic R-Au bond cleavage increased from $\mathrm{CH}_{2}\left(\mathrm{SiMe}_{3}\right)$ to $\mathrm{C}_{6} \mathrm{~F}_{5}$ which reflects the tendency for $\mathrm{C}_{6} \mathrm{~F}_{5}$ ligands to resist reductive elimination. Exchanging
$\mathrm{PH}_{3}$ for $\mathrm{H}_{2}-\mathrm{NHC}$ resulted in an increase in both $\mathrm{Au}-\mathrm{L}$ dissociation energy and R-Au homolytic bond cleavage energy, which is due to the relatively higher electron donating ability of the $\mathrm{NHC}$ ligand. The $\mathrm{Au}-\mathrm{L}$ bond dissociation energies increased from $\mathrm{CH}_{2}\left(\mathrm{SiMe}_{3}\right)$ to $\mathrm{C}_{6} \mathrm{~F}_{5}$ and from $\mathrm{PMe}_{3}$ to $\mathrm{NHC}$ which is reflective of the $\sigma$-withdrawing capability of the $\mathrm{C}_{6} \mathrm{~F}_{5}$ ligand as well as the increased $\sigma$-donor ability of the $\mathrm{NHC}$ compared to $\mathrm{PMe}_{3}$.

Compounds $\mathbf{2 a}$ and $\mathbf{3 a}$ show significantly higher $\mathrm{Au}-\mathrm{L}$ bond dissociation energy than $2 \mathrm{a}^{*}$ and $3 \mathrm{a}^{*}$ since $\mathrm{PH}_{3}$ is a much worse $\sigma$-donor than $\mathrm{PMe}_{3}$ due to the electron donating Me groups being directly bound to the ligating atom $(P)$. The change in $\mathrm{N}$-substituents in the NHC compounds has comparatively little effect on the $A u-L$ bond strength since the alkyl group is relatively remote from the ligating $C$ atom. Compounds $\mathbf{2} \mathbf{d}^{*}$ and 3d* were calculated to have $A u-L$ bond dissociation energies that were comparable to $\mathbf{2} \mathbf{d}$ and $\mathbf{3 d}$.

Thermal stability observed by DSC correlates well to the calculated $\mathrm{Au}-\mathrm{L}$ bond dissociation energies (Figure 10). Since the decomposition of these compounds is known to proceed via the rate-limiting step of $\mathrm{Au}-\mathrm{L}$ bond dissociation, a linear correlation between the observed decomposition temperature and the calculated $\mathrm{Au}-\mathrm{L}$ bond dissociation energy is expected and is observed for these compounds. The calculational and experimental thermal results corroborate each other.

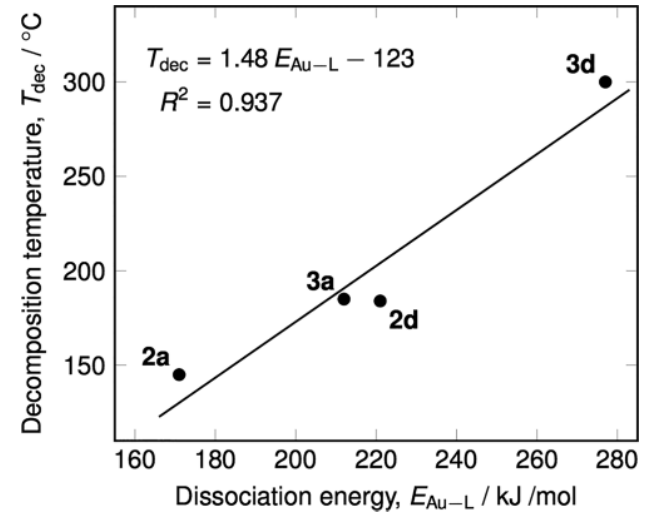

Figure 10. Correlation between ab initio-calculated $\mathrm{Au}-\mathrm{L}$ bond dissociation energies and the observed self-decomposition temperatures for $\mathbf{2} \mathbf{a}, \mathbf{d}$ and 3a,d

Being able to predict a compound's thermal stability from ligand choice is a useful tool that allows for rational design and 
theoretical evaluation of different ligand classes before undertaking synthesis and testing. Furthermore, for a single type of ligand, if the nature of alkyl groups has little effect on the overall thermal stability of the compound (such as $\mathbf{3} \mathbf{d}^{\mathbf{*}} \approx \mathbf{3} \mathbf{d}$ ) then these alkyl groups can be repurposed to introduce volatility or other desirable properties for the potential precursor. The implementation of this strategy is of ongoing interest to us in the further development of vapor deposition precursors for $\mathrm{Au}$ and other metals.

\section{Conclusions}

A family of 12 gold(I) compounds were synthesized and analyzed for their use as potential precursors for gold metal vapor deposition applications. Single crystal X-ray diffraction was used to structurally characterize 8 of these compounds to assess the effect of the anionic and coordinative ligands on intermolecular interactions. Compounds with $\mathrm{Me}$ and $\mathrm{CH}_{2}\left(\mathrm{SiMe}_{3}\right)$ ligands displayed fewer intermolecular interactions than those with $\mathrm{C}_{6} \mathrm{~F}_{5}$ ligands due to the ability of the latter to undergo $\pi$-stacking and $\mathrm{p}-\pi$ interactions. These strong intermolecular interacctions resulted in a substantial decrease in the volatility of $\mathrm{C}_{6} \mathrm{~F}_{5}$-containing compounds. Ylide compound $\mathbf{3} \mathbf{b}$ displays more intermolecular interactions than TMS-ylide compound 3c, which translated to an increase in volatility of TMS-ylide containing compounds vs. their ylide counterparts. TGA and DSC were used to assess the volatility and thermal stability of the family of compounds, and it was found that $\mathrm{CH}_{2}\left(\mathrm{SiMe}_{3}\right)$ provides higher kinetic stability than $\mathrm{Me}$. $\mathrm{NHC}$ and $\mathrm{C}_{6} \mathrm{~F}_{5}$ ligands provide substantially higher thermodynamic stability to the gold(I) center, but adversely affected volatility. To deconvolute these effects we derived a figure of merit with which the viability of all gold(I) compounds may be compared for vapor deposition. 3d has the highest merit, but is only useful at high delivery temperatures, while $\mathbf{2} \mathbf{a}$ is most suitable for lower delivery temperature applications. We are currently studying these two compounds as precursors in ALD process development. Using DFT we found a linear correlation between the calculated $\mathrm{Au}-\mathrm{L}$ bond strength and the measured onset of self-decomposition as measured by DSC. In future studies, using this computational method for the design of vapor deposition precursors should inform the process of potential candidates prior to undertaking chemical synthesis.

\section{Experimental Section}

Crystallography: A crystal of the desired compound was mounted from Paratone- $\mathrm{N}$ oil on an appropriately sized MiTeGen MicroMount. The data were collected on a Bruker APEX II chargecoupled-device (CCD) diffractometer, with an Oxford 700 Cryocool sample cooling device. The instrument was equipped with graphitemonochromated Mo- $K_{\alpha}$ radiation $(\lambda=0.71073 \AA \AA 30 \mathrm{~mA}, 50 \mathrm{mV})$, with MonoCap X-ray source optics. For data collection, four $\omega$-scan frame series were collected with $0.5^{\circ}$ wide scans, 5-30 second frames and 366 frames per series at varying $\varphi$ angles $\left(\varphi=0^{\circ}, 90^{\circ}\right.$, $180^{\circ}, 270^{\circ}$ ). Data collection, unit cell refinement, data processing and multi-scan absorption correction were applied using the $A P E X 2^{[11]}$ or $A P E X 3^{[12]}$ software packages. The structures were solved using SHELXT ${ }^{[13]}$ and all non-hydrogen atoms were refined anisotropically with SHELXL ${ }^{[14]}$ using a combination of shelXle ${ }^{[15]}$ and OLEX2 ${ }^{[16]}$ graphical user interfaces. Unless otherwise noted, all hydrogen atom positions were idealized and ride on the atom to which they were attached. The final refinement included anisotropic temperature factors on all non-hydrogen atoms.

CCDC 19155449 (for 1c), 1915544 (for 1d), 1915551 (for 2b), 1915545 (for 2d), 1915547 (for 3a), 1915550 (for 3b), 1915548 (for 3c), and 1915546 (for 3d) contain the supplementary crystallographic data for this paper. These data can be obtained free of charge from The Cambridge Crystallographic Data Centre.

Thermogravimetric Analysis (TGA) and Differential Scanning Calorimetry (DSC): TGA was performed on a TA Instruments Q500 instrument which was housed in a nitrogen-filled MBraun glovebox. The purge gas during TGA and DSC experiments was nitrogen gas of $(99.999 \%, 5.0)$ and $(99.998 \%, 4.8)$ respectively. In a typical TGA experiment $10.000 \pm 2 \mathrm{mg}$ of analyte was placed in a platinum pan whose mass was monitored by the instrument during the analysis. For DSC experiments, due to the volatile nature of the analytes and their decomposition products, mass loadings greater than $1.000 \mathrm{mg}$ often lead to a rupturing of the hermetically sealed aluminum pans. Thus, small mass loadings of $0.300 \pm 0.200 \mathrm{mg}$ were used for typical DSC experiment. DSC samples were hermetically sealed in aluminum pans inside the glovebox before analysis. Both TGA and DSC temperature ramp rates were $10.0^{\circ} \mathrm{C} / \mathrm{min}$. Langmuir vapor pressure equations were derived from TGA data using a previously reported method with $\mathrm{Cu}(\mathrm{tmhd})_{2}$ as the calibrant. ${ }^{[39,44]}$

\section{Synthetic Procedures}

CAUTION: After synthesizing the compounds in this manuscript, we learned that suspensions of pentafluorophenyllithium ${ }^{[45]}$ have been reported to explode violently upon standing even when prepared at $-78{ }^{\circ} \mathrm{C}$ under inert atmosphere. People performing this reaction have been seriously injured by such explosions in other laboratories. We must therefore recommend that the reaction to prepare pentafluorophenyllithium and its subsequent use to synthesize (THT)AuC6F5 be performed behind a blast shield in small amounts, or not at all.

\section{General Details}

All manipulations were performed under an inert atmosphere of dry nitrogen gas using an MBraun Labmaster 130 glovebox or standard Schlenk techniques unless otherwise stated. All synthesized compounds were treated as light sensitive materials during synthetic procedures and were stored at $-35{ }^{\circ} \mathrm{C}$ in the freezer of a glovebox. NMR spectra were collected at room temperature on a Bruker $300 \mathrm{MHz}$ or a Jeol $400 \mathrm{MHz}$ spectrometer and were referenced to an internal standard of tetramethylsilane (TMS) in the case of $\mathrm{CDCl}_{3}$ or residual protio solvent signal in the case of $\mathrm{C}_{6} \mathrm{D}_{6}$ (7.16 ppm relative to TMS). $C_{6} D_{6}$ was purchased from Aldrich and was degassed using freeze-pump-thaw cycles and subsequently stored over activated $4 \AA$ molecular sieves under inert gas. Trimethylmethylene phosphorane (Ylide), trimethyl(trimethylsilylmethylene) phosphorane (TMS-ylide), ${ }^{[46]}$ (THT)AuCl, $\left(\mathrm{PMe}_{3}\right) \mathrm{AuCl}^{\left[{ }^{[4]}\right.}$ and $N, N^{\prime}$-di-tert-butylimidazolidinium chloride ${ }^{[48]}$ were prepared according to literature procedures. Trimethylphosphine $\left(\mathrm{PMe}_{3}\right)$ was prepared by the literature procedure using iodomethane instead of bromomethane. ${ }^{[49]}$ Tetrahydrothiophene pentafluorophenylgold(I), (THT)AuC $\mathrm{F}_{5}$, was prepared using chloropentafluorophenylbenzene instead of the bromo- derivative. ${ }^{[45]}$ Methyllithium (1.6 $\mathrm{M}$ in diethyl ether), (trimethylsilyl)methyllithium (1.0 $\mathrm{M}$ in pentane), $n$-butyllithium (1.6 $\mathrm{M}$ in hexanes), potassium hydride (30 weight \% dispersion in mineral oil), sodium tert-butoxide, tetrahydrofuran (anhydrous), 
pentane (anhydrous), and dichloromethane (anhydrous) were purchased from Aldrich and used as received. Diethyl ether, hexanes, and toluene were purchased from VWR chemicals and purified using an MBraun solvent purification system prior to use. Gold metal (99.99\%) was purchased at market price and was used as received. $\mathrm{HAuCl}_{4} \cdot \times \mathrm{H}_{2} \mathrm{O}$ was obtained from the digestion of gold metal by chlorine gas as described previously, with the modification of using up to 1 Troy ounce of $(32.2 \mathrm{~g})$ gold metal in $250 \mathrm{~mL}$ of $\mathrm{H}_{2} \mathrm{O}$.

Elemental analysis was performed by the elemental analysis laboratory at the Université de Montréal.

$\mathbf{N}, \mathbf{N}^{\prime}$-Di-tert-butylimidazolidin-2-ylidene: A modification of a previously reported procedure was used. ${ }^{[32]}$ To a $500 \mathrm{~mL}$ Schlenk flask containing $150 \mathrm{~mL}$ of tetrahydrofuran was added $10.01 \mathrm{~g}$ (45.76 mmol) of dry $\mathrm{N}, \mathrm{N}$-di-tert-butylimidazolidinium chloride, $4.366 \mathrm{~g}$ (181.9 mmol) of sodium hydride, $0.262 \mathrm{~g}(2.7 \mathrm{mmol})$ of sodium tert-butoxide, and a teflon-coated stir bar. This white suspension was sealed and stirred overnight, at which time it was filtered through a plug of celite in a medium frit into a $250 \mathrm{~mL}$ Schlenk flask which contained a Teflon-coated stir bar. Approximately two-thirds of the THF was removed by evaporation, then the flask was cooled in a $-20{ }^{\circ} \mathrm{C}$ bath and the residual tetrahydrofuran was stripped under high vacuum leaving an off-white solid in the flask which is the frozen free carbene product. This solid was then purified by static high-vacuum ( 10 mTorr) distillation using a warm water pot flask (approx. $40{ }^{\circ} \mathrm{C}$ ) and a $-78{ }^{\circ} \mathrm{C}$ receiving flask. The clear crystalline solid caught in the receiving flask was warmed to room temperature and liquify under nitrogen, and was then transferred into a glovebox for storage in a $-35^{\circ} \mathrm{C}$ freezer. Yield $=$ $7.501 \mathrm{~g}, 90 \%$. NMR analysis was consistent with the reported literature values.

Trimethylphosphine Methylgold(I), (PMe $)_{3}$ AuMe (1a): $4.151 \mathrm{~g}$ (13.46 mmol) of $\left(\mathrm{PMe}_{3}\right) \mathrm{AuCl}$ was suspended in $150 \mathrm{~mL}$ of diethyl ether and cooled to $-78{ }^{\circ} \mathrm{C}$. Then, $8.41 \mathrm{~mL}(1.6 \mathrm{M}$ in diethyl ether, $13.50 \mathrm{~mol}$ ) of methyllithium solution was then added dropwise over 5 minutes. The resulting yellow suspension was stirred at $-78{ }^{\circ} \mathrm{C}$ for 1 hour, and was then warmed to room temperature, at which point the colour of the suspension had returned to white. Then the reaction mixture was cooled to $0{ }^{\circ} \mathrm{C}$ and quenched by adding $20 \mathrm{~mL}$ of distilled and degassed water dropwise. The resulting biphasic mixture was separated, and the ethereal layer was dried with $\mathrm{MgSO}_{4}$. After filtration the solvent was removed using a rotary evaporator leaving a slightly purple crystalline solid. This material was purified by sublimation $\left(50^{\circ} \mathrm{C}, 10 \mathrm{mTorr}\right)$ which gave a white crystalline solid and left a purple-brown coloured residue in the pot. Yield $3.007 \mathrm{~g}$ (77\%). $T_{\mathrm{m}}(\mathrm{DSC})=62{ }^{\circ} \mathrm{C} .{ }^{1} \mathrm{H}-\mathrm{NMR}\left(300 \mathrm{MHz}, \mathrm{C}_{6} \mathrm{D}_{6}\right): \delta=1.22(\mathrm{~d}$, $\left.{ }^{3} J_{H-P}=8.7 \mathrm{~Hz}, 3 \mathrm{H}, \mathrm{Au}-\mathrm{CH}_{3}\right), 0.62\left(\mathrm{~d},{ }^{2} J_{H-P}=8.7 \mathrm{~Hz}, 9 \mathrm{H}, \mathrm{P}-\mathrm{CH}_{3}\right) .{ }^{13} \mathrm{C}-$ NMR $\left(75.5 \mathrm{MHz}, \mathrm{C}_{6} \mathrm{D}_{6}\right): \delta=15.56\left(\mathrm{~d},{ }^{1} J_{\mathrm{C}-\mathrm{P}}=29.1 \mathrm{~Hz}, \mathrm{P}-\mathrm{CH}_{3}\right), 8.73(\mathrm{~d}$, $\left.{ }^{2} J_{C-P}=102.5 \mathrm{~Hz}, \mathrm{Au}-\mathrm{CH}_{3}\right) .{ }^{31} \mathrm{P}-\mathrm{NMR}\left(121.5 \mathrm{MHz}, \mathrm{C}_{6} \mathrm{D}_{6}\right): \delta=13.84$.

Methyl(trimethylphosphoniummethylide)gold(I), (Ylide)AuMe (1b): Modifying the previously reported procedure, ${ }^{[46]} 0.144 \mathrm{~g}$ $(0.501 \mathrm{mmol})$ of $\left(\mathrm{PMe}_{3}\right)$ AuMe was dissolved in $10 \mathrm{~mL}$ of diethyl ether. To this was added $0.050 \mathrm{~mL}(\rho=0.90 \mathrm{~g} / \mathrm{mL}$. $0.499 \mathrm{mmol})$ of neat trimethylphosphoniummethylide (ylide) which immediately produced a white precipitate. This suspension was stirred for one hour, filtered through a medium frit, washed with $3 \times 1 \mathrm{~mL}$ of cold pentane and dried under high vacuum. Yield $=0.131 \mathrm{~g}, 87 \%$ of a white powder. $T_{\mathrm{m}}(\mathrm{DSC})=\mathrm{N} / \mathrm{A}$. Decomposition begins at $107^{\circ} \mathrm{C}$. ${ }^{1} \mathrm{H}-\mathrm{NMR}\left(300 \mathrm{MHz}, \mathrm{C}_{6} \mathrm{D}_{6}\right): \delta=1.16\left(\mathrm{~d},{ }^{4} \mathrm{~J}_{\mathrm{H}-\mathrm{P}}=1.2 \mathrm{~Hz}, 3 \mathrm{H}, \mathrm{Au}-\mathrm{CH}_{3}\right)$, $0.61\left(\mathrm{~d},{ }^{2} J_{H-P}=12.9 \mathrm{~Hz}, 9 \mathrm{H}, \mathrm{P}-\mathrm{CH}_{3}\right), 0.45\left(\mathrm{~d},{ }^{2} J_{H-P}=12.6 \mathrm{~Hz}, 2 \mathrm{H}\right.$, P-CH $) .{ }^{13} \mathrm{C}-\mathrm{NMR}\left(75.5 \mathrm{MHz}, \mathrm{C}_{6} \mathrm{D}_{6}\right): \delta=18.02\left(\mathrm{~d},{ }^{1} J_{\mathrm{C}-\mathrm{P}}=36.8 \mathrm{~Hz}\right.$, $\left.\mathrm{P}-\mathrm{CH}_{2}\right), 15.11\left(\mathrm{~d},{ }^{1} J_{C-P}=56.2 \mathrm{~Hz}, \mathrm{P}-\mathrm{CH}_{3}\right), 2.52\left(\mathrm{~d},{ }^{3} J_{C-P}=3.0 \mathrm{~Hz}\right.$, $\left.\mathrm{Au}-\mathrm{CH}_{3}\right) .{ }^{31} \mathrm{P}-\mathrm{NMR}\left(121.5 \mathrm{MHz}, \mathrm{C}_{6} \mathrm{D}_{6}\right): \delta=25.83$.
Methyl[trimethylphosphonium(trimethylsilyl)methylide]gold(I), (TMS-ylide)AuMe (1c): Modifying the previously reported procedure, ${ }^{[30]} 0.106 \mathrm{~g}(0.368 \mathrm{mmol})$ of $\left(\mathrm{PMe}_{3}\right)$ AuMe was dissolved in $10 \mathrm{~mL}$ of diethyl ether. To this was added $0.114 \mathrm{~g}(0.702 \mathrm{mmol})$ trimethylphosphonium(trimethylsilyl)methylide (TMS-ylide) and the solution was stirred overnight. The solvent was removed under high vacuum resulting leaving an off-white solid. Yield $=0.117 \mathrm{~g}$ (84\%). Crystals of this compound suitable for X-ray crystallography were grown from hot toluene. $T_{\mathrm{m}}(\mathrm{DSC})=129{ }^{\circ} \mathrm{C}$ (dec.). ${ }^{1} \mathrm{H}-\mathrm{NMR}$ $\left(300 \mathrm{MHz}, \mathrm{C}_{6} \mathrm{D}_{6}\right): \delta=1.16\left(\mathrm{~d},{ }^{4} J_{\mathrm{H}-\mathrm{P}}=0.9 \mathrm{~Hz}, 3 \mathrm{H}, \mathrm{Au}-\mathrm{CH}_{3}\right), 0.72(\mathrm{~d}$, $\left.{ }^{2} J_{H-P}=12.6 \mathrm{~Hz}, 9 \mathrm{H}, \mathrm{P}-\mathrm{CH}_{3}\right), 0.25\left(\mathrm{~s}, 9 \mathrm{H}, \mathrm{Si}-\mathrm{CH}_{3}\right),-0.17\left(\mathrm{~d},{ }^{2} J_{\mathrm{H}-\mathrm{P}}=\right.$ $\left.18.3 \mathrm{~Hz}, 1 \mathrm{H}, \mathrm{P}-\mathrm{CH}_{3}\right) .{ }^{13} \mathrm{C}-\mathrm{NMR}\left(75.5 \mathrm{MHz}, \mathrm{C}_{6} \mathrm{D}_{6}\right): \delta=17.20\left(\mathrm{~d},{ }^{1} J_{\mathrm{C}-\mathrm{P}}=\right.$ $\left.54.1 \mathrm{~Hz}, \mathrm{P}-\mathrm{CH}_{3}\right), 16.58\left(\mathrm{~d},{ }^{1} J_{\mathrm{C}-\mathrm{P}}=33.4 \mathrm{~Hz}, \mathrm{P}-\mathrm{CH}_{2}\right), 4.46\left(\mathrm{~d},{ }^{3} J_{\mathrm{C}-\mathrm{P}}=\right.$ $\left.4.7 \mathrm{~Hz}, \mathrm{Si}-\mathrm{CH}_{3}\right), 0.77\left(\mathrm{~d},{ }^{3} \mathrm{~J}_{\mathrm{C}-\mathrm{P}}=4.0 \mathrm{~Hz}, \mathrm{Au}-\mathrm{CH}_{3}\right) .{ }^{31} \mathrm{P}-\mathrm{NMR}(121.5 \mathrm{MHz}$, $\left.\mathrm{C}_{6} \mathrm{D}_{6}\right): \delta=20.00$.

*Note: The excess of TMS-ylide was necessary to push the reaction to completion. 1:1 stoichiometry only converted $75 \%$ of $\mathbf{1 a}$ to $\mathbf{1 c}$.

N,N'-Di-tert-butylimidazolidin-2-ylidene(methyl)gold(I), (NHC)AuMe (1 d): $1.554 \mathrm{~g}(5.40 \mathrm{mmol})$ of $\left(\mathrm{PMe}_{3}\right)$ AuMe and $1.588 \mathrm{~g}$ (8.71 mmol) of $N, N^{\prime}$-di-tert-butylimidazolidin-2-ylidene were added to $30 \mathrm{~mL}$ of toluene and the solution was stirred overnight. The next day, a very small amount of purple precipitate was present in the otherwise clear solution. The solution was filtered through a medium frit, and the solvent was removed under high vacuum. Then the material was dried for a further 3 hours at $40{ }^{\circ} \mathrm{C}$ under high vacuum to remove excess free NHC. The resulting slightly purple white solid was then purified by sublimation $\left(100^{\circ} \mathrm{C}, 10 \mathrm{mTorr}\right)$ giving a white crystalline solid. Yield $=2.002 \mathrm{~g}$ (94\%). Crystals of this compound suitable for X-ray crystallography were grown from hot toluene. $T_{\mathrm{m}}(\mathrm{DSC})=111^{\circ} \mathrm{C}$. Elemental analysis: Calcd. for $\mathrm{C}_{12} \mathrm{H}_{25} \mathrm{~N}_{2} \mathrm{Au}$ : C, 36.51; H, 6.34; N, 7.10; found $\mathrm{C}, 36.60 ; \mathrm{H}, 6.26$; $\mathrm{N}$, 6.97. ${ }^{1} \mathrm{H}-\mathrm{NMR}\left(300 \mathrm{MHz}, \mathrm{C}_{6} \mathrm{D}_{6}\right): \delta=2.65\left(\mathrm{~s}, 4 \mathrm{H}, \mathrm{CH}_{2}-\mathrm{CH}_{2}\right), 1.52$ $\left[\mathrm{s}, 18 \mathrm{H}, \mathrm{C}\left(\mathrm{CH}_{3}\right)_{3}\right], 1.20\left(\mathrm{~s}, 3 \mathrm{H}, \mathrm{Au}-\mathrm{CH}_{3}\right) .{ }^{13} \mathrm{C}-\mathrm{NMR}\left(75.5 \mathrm{MHz}, \mathrm{C}_{6} \mathrm{D}_{6}\right)$ : $\delta=221.74(\mathrm{~s}, \mathrm{NCN}), 56.15\left[\mathrm{~s}, \mathrm{C}\left(\mathrm{CH}_{3}\right)_{3}\right], 46.31\left(\mathrm{~s}, \mathrm{CH}_{2}-\mathrm{CH}_{2}\right), 31.35$ $\left[\mathrm{s}, \mathrm{C}\left(\mathrm{CH}_{3}\right)_{3}\right],-3.26\left(\mathrm{~s}, \mathrm{Au}-\mathrm{CH}_{3}\right)$.

*Note: The excess of free NHC was used in order to push the reaction to completion. At 1:1 stoichiometry, the starting material 1a persisted in $\approx 25 \mathrm{~mol}-\%$, and it is difficult to purify $\mathbf{1 d}$ when $\mathbf{1 a}$ is present.

Trimethylphosphine Trimethylsilylmethylgold(I), ( $\left.\mathrm{PMe}_{3}\right)$ AuNeoSi (2a): $7.80 \mathrm{~g}(25.3 \mathrm{mmol})$ of $\left(\mathrm{PMe}_{3}\right) \mathrm{AuCl}$ was suspended in $150 \mathrm{~mL}$ of diethyl ether and cooled to $-78{ }^{\circ} \mathrm{C}$. (Trimethylsilyl)methyllithium solution $(1.0 \mathrm{M}, 27.8 \mathrm{~mL}$ ) was added dropwise over 20 minutes. The mixture was then warmed to room temperature. The resulting white suspension was then cooled to $0{ }^{\circ} \mathrm{C}$ and quenched by adding $25 \mathrm{~mL}$ of distilled and degassed water dropwise over 10 minutes. The resulting biphasic mixture was separated, the brown-purple coloured water layer was washed with $2 \times 20 \mathrm{~mL}$ of diethyl ether, and the organic layers were combined and dried with $\mathrm{MgSO}_{4}$. After filtration, the solvent was removed using a rotary evaporator and the resulting dark purple liquid was purified by vacuum distillation (90 ${ }^{\circ} \mathrm{C}, 10$ mTorr) giving a clear liquid. Yield $7.735 \mathrm{~g}(85 \%)$. This compound freezes upon refrigeration at $5{ }^{\circ} \mathrm{C} .{ }^{1} \mathrm{H}-\mathrm{NMR}(300 \mathrm{MHz}$, $\left.\mathrm{C}_{6} \mathrm{D}_{6}\right): \delta=0.84\left(\mathrm{~d},{ }^{3} \mathrm{~J}_{\mathrm{H}-\mathrm{P}}=10.5 \mathrm{~Hz}, 2 \mathrm{H}, \mathrm{Au}-\mathrm{CH}_{2}\right), 0.54\left(\mathrm{~d},{ }^{2} J_{\mathrm{H}-\mathrm{P}}=\right.$ $\left.8.7 \mathrm{~Hz}, 9 \mathrm{H}, \mathrm{P}-\mathrm{CH}_{3}\right), 0.51$ (s, 9H, Si-CH $\mathrm{CH}_{3}$. ${ }^{13} \mathrm{C}-\mathrm{NMR}\left(75.5 \mathrm{MHz}, \mathrm{C}_{6} \mathrm{D}_{6}\right)$ : $\delta=15.58\left(\mathrm{~d},{ }^{2} J_{C-P}=85.7 \mathrm{~Hz}, \mathrm{Au}-\mathrm{CH}_{2}\right), 15.39\left(\mathrm{~d},{ }^{1} J_{C-P}=29.6 \mathrm{~Hz}\right.$, $\left.\mathrm{P}-\mathrm{CH}_{3}\right), 4.78\left(\mathrm{~d},{ }^{4} J_{\mathrm{C}-\mathrm{P}}=2.2 \mathrm{~Hz}, \mathrm{Si}-\mathrm{CH}_{3}\right) .{ }^{31} \mathrm{P}-\mathrm{NMR}\left(121.5 \mathrm{MHz}, \mathrm{C}_{6} \mathrm{D}_{6}\right)$ : $\delta=12.70$.

Trimethylsilylmethyl(trimethylphosphoniummethylide)gold(I), (Ylide)AuNeoSi (2b): Modifying the previously reported procedure, $^{[30]} 0.481 \mathrm{~g}(1.33 \mathrm{mmol})$ of $\left(\mathrm{PMe}_{3}\right)$ AuNeoSi was dissolved in 
$10 \mathrm{~mL}$ of diethyl ether in a glovebox. To this was added $0.233 \mathrm{~mL}$ $(\rho=0.90 \mathrm{~g} / \mathrm{mL}$. $2.33 \mathrm{mmol}$ ) of neat trimethylphosphoniummethylide (ylide). The resulting solution was stirred overnight and then dried under high vacuum leaving a white solid. Yield $0.411 \mathrm{~g}(82 \%)$. Crystals of this compound suitable for X-ray crystallography were grown from hot toluene. $T_{\mathrm{m}}(\mathrm{DSC})=134{ }^{\circ} \mathrm{C} .{ }^{1} \mathrm{H}-\mathrm{NMR}(300 \mathrm{MHz}$, $\left.\mathrm{C}_{6} \mathrm{D}_{6}\right): \delta=0.62\left(\mathrm{br}, 2 \mathrm{H}, \mathrm{Au}-\mathrm{CH}_{2}\right), 0.61\left(\mathrm{~d},{ }^{2} J_{\mathrm{H}-\mathrm{P}}=12.9 \mathrm{~Hz}, 9 \mathrm{H}, \mathrm{P}-\mathrm{CH}_{3}\right)$, $0.57\left(\mathrm{~s}, 9 \mathrm{H}, \mathrm{Si}-\mathrm{CH}_{3}\right), 0.42\left(\mathrm{~d},{ }^{2} J_{H-P}=12.6 \mathrm{~Hz}, 2 \mathrm{H}, \mathrm{P}-\mathrm{CH}_{2}\right) .{ }^{13} \mathrm{C}-\mathrm{NMR}$ $\left(75.5 \mathrm{MHz}, \mathrm{C}_{6} \mathrm{D}_{6}\right): \delta=17.36\left(\mathrm{~d},{ }^{1} J_{C-P}=37.3 \mathrm{~Hz}, \mathrm{P}-\mathrm{CH}_{2}\right), 15.04\left(\mathrm{~d},{ }^{1} J_{C-}\right.$ $\left.p=56.2 \mathrm{~Hz}, \mathrm{P}-\mathrm{CH}_{3}\right), 8.47\left(\mathrm{~d},{ }^{3} J_{\mathrm{C}-\mathrm{P}}=2.6 \mathrm{~Hz}, \mathrm{Au}-\mathrm{CH}_{2}\right), 5.01\left(\mathrm{~s}, \mathrm{Si}-\mathrm{CH}_{3}\right)$. ${ }^{31} \mathrm{P}-\mathrm{NMR}\left(121.5 \mathrm{MHz}, \mathrm{C}_{6} \mathrm{D}_{6}\right): \delta=25.51$.

Trimethylsilylmethyl[trimethylphosphonium(trimethylsilyl)methylide]gold(I), (TMS-ylide)AuNeoSi (2c): Modifying the previously reported procedure, ${ }^{[30]} 0.121 \mathrm{~g}(0.335 \mathrm{mmol})$ of $\left(\mathrm{PMe}_{3}\right)$ AuNeoSi and $0.062 \mathrm{~g}(0.382 \mathrm{mmol})$ of trimethylphosphonium(trimethylsilyl)methylide (TMS-ylide) were dissolved in $4 \mathrm{~mL}$ of pentane. The resulting solution was stirred overnight, and then the solvent was removed leaving a white crystalline solid which was purified by recrystallization from a minimum of pentane. Yield $0.084 \mathrm{~g}$ (56\%). $T_{\mathrm{m}}(\mathrm{DSC})=66{ }^{\circ} \mathrm{C} .{ }^{1} \mathrm{H}-\mathrm{NMR}\left(300 \mathrm{MHz}, \mathrm{C}_{6} \mathrm{D}_{6}\right): \delta=0.72$ $\left(\mathrm{d},{ }^{2} J_{H-P}=12.6 \mathrm{~Hz}, 9 \mathrm{H}, \mathrm{P}-\mathrm{CH}_{3}\right), 0.65\left(\mathrm{br}, 2 \mathrm{H}, \mathrm{Au}-\mathrm{CH}_{2}\right), 0.54(\mathrm{~s}, 9 \mathrm{H}$, NeoSi-CH $\left.{ }_{3}\right), 0.23\left(\mathrm{~s}, 9 \mathrm{H}\right.$, TMS-ylide-Si- $\left.\mathrm{CH}_{3}\right),-0.21\left(\mathrm{~d},{ }^{2} J_{H-P}=18.3 \mathrm{~Hz}\right.$, $1 \mathrm{H}, \mathrm{P}-\mathrm{CH}) .{ }^{13} \mathrm{C}-\mathrm{NMR}\left(75.5 \mathrm{MHz}, \mathrm{C}_{6} \mathrm{D}_{6}\right): \delta=16.72\left(\mathrm{~d},{ }^{1} J_{\mathrm{C}-\mathrm{P}}=42.7 \mathrm{~Hz}\right.$, $\left.\mathrm{P}-\mathrm{CH}_{3}\right), 15.97\left(\mathrm{~d},{ }^{1} \mathrm{~J}_{\mathrm{C}-\mathrm{P}}=27.6 \mathrm{~Hz}, \mathrm{P}-\mathrm{CH}_{2}\right), 6.94\left(\mathrm{~s}, \mathrm{Au}-\mathrm{CH}_{2}\right), 4.37(\mathrm{~s}$, NeoSi-CH $\left.\mathrm{CH}_{3}\right), 4.03\left(\mathrm{~d},{ }^{3} \mathrm{~J}_{\mathrm{C}-\mathrm{P}}=3.6 \mathrm{~Hz}\right.$, TMS-ylide-Si- $\left.\mathrm{CH}_{3}\right) .{ }^{31} \mathrm{P}-\mathrm{NMR}$ (121.5 MHz, $\left.\mathrm{C}_{6} \mathrm{D}_{6}\right): \delta=19.80$.

$\mathbf{N}, \boldsymbol{N}^{\prime}$-Di-tert-butylimidazolidin-2-ylidene(trimethylsilylmethyl)gold(I), (NHC)AuNeoSi (2d): $1.551 \mathrm{~g}(4.31 \mathrm{mmol})$ of $\left(\mathrm{PMe}_{3}\right) \mathrm{AuNeOSi}$ and $0.794 \mathrm{~g}(4.36 \mathrm{mmol})$ of $N, N^{\prime}$-di-tert-butylimidazolidin-2-ylidene were added to $30 \mathrm{~mL}$ of diethyl ether and the solution was stirred overnight. The next day, the solution was evaporated to dryness leaving a white crystalline material. Then the material was dried for a further 3 hours at $40{ }^{\circ} \mathrm{C}$ under high vacuum to remove excess free NHC. The resulting white solid was then purified by sublimation (100 to $120{ }^{\circ} \mathrm{C}, 10$ mTorr) giving a white crystalline solid. Yield $=$ $1.754 \mathrm{~g}(87 \%)$. Crystals of this compound suitable for X-ray crystallography were grown from hot toluene. $T_{\mathrm{m}}(\mathrm{DSC})=105^{\circ} \mathrm{C}$. Elemental analysis: Calcd for $\mathrm{C}_{15} \mathrm{H}_{33} \mathrm{~N}_{2}$ AuSi: $\mathrm{C}, 38.58 ; \mathrm{H}, 7.07 ; \mathrm{N}, 6.00$; found C, 37.95; $\mathrm{H}, 6.97 ; \mathrm{N}, 5.67 .{ }^{1} \mathrm{H}-\mathrm{NMR}\left(300 \mathrm{MHz}, \mathrm{C}_{6} \mathrm{D}_{6}\right): \delta=2.58(\mathrm{~s}, 4 \mathrm{H}$, $\left.\mathrm{CH}_{2}-\mathrm{CH}_{2}\right), 1.49\left[\mathrm{~s}, 18 \mathrm{H}, \mathrm{C}\left(\mathrm{CH}_{3}\right)_{3}\right], 0.75\left(\mathrm{~s}, 2 \mathrm{H}, \mathrm{Au}-\mathrm{CH}_{2}\right), 0.54(\mathrm{~s}, 9 \mathrm{H}$, $\left.\mathrm{Si}-\mathrm{CH}_{3}\right) .{ }^{13} \mathrm{C}-\mathrm{NMR}\left(75.5 \mathrm{MHz}, \mathrm{C}_{6} \mathrm{D}_{6}\right): \delta=219.94(\mathrm{NCN}), 56.15$ $\left[\mathbf{C}\left(\mathrm{CH}_{3}\right)_{3}\right], 46.23\left(\mathrm{CH}_{2}-\mathrm{CH}_{2}\right), 31.26\left[\mathrm{C}\left(\mathrm{CH}_{3}\right)_{3}\right], 4.30\left(\mathrm{Si}-\mathrm{CH}_{3}\right), 3.30(\mathrm{Au}-$ $\mathrm{CH}_{2}$ ).

Trimethylphosphine(pentafluorophenyl)gold(I), $\left(\mathrm{PMe}_{3}\right) \mathrm{AuC}_{6} \mathrm{~F}_{5}$ (3a): $0.550 \mathrm{~g}$ (1.22 mmol) of (THT)AuC $\mathrm{F}_{5}$ and $0.142 \mathrm{~g}(1.82 \mathrm{mmol})$ of $\mathrm{PMe}_{3}$ were dissolved in $15 \mathrm{~mL}$ of diethyl ether and the solution was stirred overnight. The next day the solution was filtered through a medium frit and the solvents evaporated to dryness leaving a white solid. This solid was then purified by sublimation (100 to $\left.120{ }^{\circ} \mathrm{C}, 10 \mathrm{mTorr}\right)$. Yield $=0.503 \mathrm{~g}(94 \%)$. Crystals of this compound suitable for X-ray crystallography were grown from hot toluene. $T_{\mathrm{m}}(\mathrm{DSC})=151{ }^{\circ} \mathrm{C} .{ }^{1} \mathrm{H}-\mathrm{NMR}\left(300 \mathrm{MHz}, \mathrm{CDCl}_{3}\right): \delta=1.51(\mathrm{~d}$, $\left.{ }^{2} J_{H-P}=8.1 \mathrm{~Hz}, 9 \mathrm{H}, \mathrm{P}-\mathrm{CH}_{3}\right) .{ }^{13} \mathrm{C}-\mathrm{NMR}\left(75.5 \mathrm{MHz}, \mathrm{CDCl}_{3}\right): \delta=15.64$ $\left(d^{1}{ }^{1} J_{C-P}=35.2 \mathrm{~Hz}, \mathrm{P}-\mathrm{CH}_{3}\right) .{ }^{31} \mathrm{P}-\mathrm{NMR}\left(121.5 \mathrm{MHz}, \mathrm{CDCl}_{3}\right): \delta=-5.00$. ${ }^{19} \mathrm{~F}-\mathrm{NMR}\left(282.4 \mathrm{MHz}, \mathrm{CDCl}_{3}\right): \delta=-118.51$ (m, ortho-F), $-160.63(\mathrm{t}$, ${ }^{3} J_{\mathrm{F}-\mathrm{F}}=19.8 \mathrm{~Hz}$, para-F), $-164.49(\mathrm{~m}$, meta-F).

Pentafluorophenyl(trimethylphosphoniummethylide)gold(I), (Ylide) $\mathrm{AuC}_{6} \mathbf{F}_{\mathbf{5}}$ (3b): $0.120 \mathrm{~g}(0.273 \mathrm{mmol})$ of $\left(\mathrm{PMe}_{3}\right) \mathrm{AuC}_{6} \mathrm{~F}_{5}$ and $0.031 \mathrm{~mL}(\rho=0.90 \mathrm{~g} / \mathrm{mL}$. $0.310 \mathrm{mmol}$ ) of trimethylphosphoniummethylide (ylide) were added to $5 \mathrm{~mL}$ of diethyl ether which caused a white precipitate to form. The mixture was stirred for one hour and then filtered, washes with diethyl ether and dried under high vacuum giving a white crystalline solid. This material was purified by recrystallization from hot toluene, which also produced crystals that were suitable for X-ray crystallography. Yield $=0.080 \mathrm{~g}(65 \%)$. $T_{\mathrm{m}}(\mathrm{DSC})=157^{\circ} \mathrm{C}$. Elemental analysis: Calcd for $\mathrm{C}_{10} \mathrm{H}_{11} \mathrm{AuF}_{5} \mathrm{P}: \mathrm{C}$, 26.42; $\mathrm{H}, 2.42$; found $\mathrm{C}, 26.59 ; \mathrm{H}, 2.50 .{ }^{1} \mathrm{H}-\mathrm{NMR}\left(300 \mathrm{MHz}, \mathrm{C}_{6} \mathrm{D}_{6}\right): \delta=$ $0.56\left(\mathrm{~d}^{2}{ }^{2} J_{\mathrm{H}-\mathrm{P}}=9.6 \mathrm{~Hz}, 2 \mathrm{H}, \mathrm{P}-\mathrm{CH}_{2}\right), 0.42\left(\mathrm{~d},{ }^{2} J_{H-P}=9.6 \mathrm{~Hz}, 9 \mathrm{H}, \mathrm{P}-\mathrm{CH}_{3}\right)$. ${ }^{13} \mathrm{C}-\mathrm{NMR}\left(75.5 \mathrm{MHz}, \mathrm{C}_{6} \mathrm{D}_{6}\right): \delta=14.26\left(\mathrm{~d},{ }^{1} \mathrm{~J}_{\mathrm{C}-\mathrm{P}}=42.7 \mathrm{~Hz}, \mathrm{P}-\mathrm{CH}_{3}\right)$, $12.52\left(\mathrm{~d},{ }^{1} J_{\mathrm{C}-\mathrm{P}}=28.9 \mathrm{~Hz}, \mathrm{P}-\mathrm{CH}_{2}\right) .{ }^{31} \mathrm{P}-\mathrm{NMR}\left(121.5 \mathrm{MHz}, \mathrm{C}_{6} \mathrm{D}_{6}\right): \delta=$ 26.50. ${ }^{19} \mathrm{~F}-\mathrm{NMR}\left(282.4 \mathrm{MHz}, \mathrm{C}_{6} \mathrm{D}_{6}\right): \delta=-116.23$ (m, ortho-F), -161.29 $\left(\mathrm{t},{ }^{3} J_{\mathrm{F}-\mathrm{F}}=15.2 \mathrm{~Hz}\right.$, para-F), $-162.86(\mathrm{~m}$, meta-F).

Pentafluorophenyl[trimethylphosphonium(trimethylsilyl)methylide]gold(I), (TMS-ylide)AuC $\mathbf{F}_{6} \mathbf{F}_{5}$ (3c): $0.478 \mathrm{~g}$ (2.94 mmol) of trimethylphosphonium(trimethylsilyl)methylide (TMS-ylide) was added to a solution of $1.070 \mathrm{~g}\left(2.45 \mathrm{mmol}\right.$ ) (THT)AuC ${ }_{6} \mathrm{~F}_{5}$ in $10 \mathrm{~mL}$ of diethyl ether causing a white precipitate to form immediately. The suspension was allowed to stir overnight and was then stripped of its solvent, re-dissolved in a minimum of toluene, filtered, and left in a $-35^{\circ} \mathrm{C}$ freezer overnight to recrystallize. Clear platelike crystals were observed in a mother liquor of brown-red solution. These crystals were of suitable quality for crystallography $(0.211 \mathrm{~g}, 33 \%)$. A second batch of crystals was grown by concentrating the mother liquor by $2 / 3$, filtering and storing at $-35{ }^{\circ} \mathrm{C}$ overnight $(0.114 \mathrm{~g}, 18 \%)$. Yield $=0.325 \mathrm{~g}(51 \%) . T_{\mathrm{m}}(\mathrm{DSC})=150^{\circ} \mathrm{C}$. Elemental analysis: Calcd for $\mathrm{C}_{13} \mathrm{H}_{19} \mathrm{AuF}_{5} \mathrm{PSi}$ : C, 29.64; $\mathrm{H}, 3.61$; found $\mathrm{C}, 29.37$; $\mathrm{H}, 3.76 .{ }^{1} \mathrm{H}-\mathrm{NMR}\left(300 \mathrm{MHz}, \mathrm{C}_{6} \mathrm{D}_{6}\right): \delta=0.62\left(\mathrm{~d},{ }^{2} J_{\mathrm{H}-\mathrm{P}}=12.6 \mathrm{~Hz}, 9 \mathrm{H}\right.$, $\left.\mathrm{P}-\mathrm{CH}_{3}\right), 0.17\left(\mathrm{~s}, \mathrm{Si}-\mathrm{CH}_{3}\right), 0.03\left(\mathrm{~d}^{2}{ }^{2} \mathrm{~J}_{\mathrm{H}-\mathrm{P}}=18.3 \mathrm{~Hz}, 1 \mathrm{H}, \mathrm{P}-\mathrm{CH}\right) .{ }^{13} \mathrm{C}-\mathrm{NMR}$ $\left(75.5 \mathrm{MHz}, \mathrm{C}_{6} \mathrm{D}_{6}\right): \delta=16.61\left(\mathrm{~d},{ }^{1} J_{\mathrm{C}-\mathrm{P}}=57.2 \mathrm{~Hz}, \mathrm{P}-\mathrm{CH}_{3}\right), 13.20(\mathrm{~d}$, $\left.{ }^{1} J_{C-P}=36.4 \mathrm{~Hz}, \mathrm{P}-\mathrm{CH}\right), 4.14\left(\mathrm{~d},{ }^{3} J_{\mathrm{C}-\mathrm{P}}=4.6 \mathrm{~Hz}, \mathrm{Si}-\mathrm{CH}_{3}\right) .{ }^{31} \mathrm{P}-\mathrm{NMR}$ (121.5 MHz, $\left.\mathrm{C}_{6} \mathrm{D}_{6}\right): \delta=23.65 .{ }^{19} \mathrm{~F}-\mathrm{NMR}\left(282.4 \mathrm{MHz}, \mathrm{C}_{6} \mathrm{D}_{6}\right): \delta=$ $-118.67\left(\mathrm{~m}\right.$, ortho-F), $-163.36\left(\mathrm{t},{ }^{3} \mathrm{~J}_{\mathrm{F}-\mathrm{F}}=20.3 \mathrm{~Hz}\right.$, para-F), $-165.07(\mathrm{~m}$, meta-F).

$N, N^{\prime}$-Di-tert-butylimidazolidin-2-ylidene(pentafluorophenyl)gold(I), (NHC)AuC ${ }_{6} F_{5}$ (3d): $0.278 \mathrm{~g}(0.615 \mathrm{mmol})$ of (THT)AuC $\mathrm{C}_{6} \mathrm{~F}_{5}$ and $0.168 \mathrm{~g}(0.922 \mathrm{mmol})$ of $N, N^{\prime}$-di-tert-butylimidazolidin-2-ylidene were dissolved in $5 \mathrm{~mL}$ of diethyl ether and the solution was stirred overnight. The solvent was removed, and the residue was extracted with $3 \times 3 \mathrm{~mL}$ of toluene, filtered, and dried under high vacuum at $40{ }^{\circ} \mathrm{C}$ for at least 3 hours to remove excess free NHC, leaving a slightly purple solid. This material was purified by sublimation ( 110 to $130{ }^{\circ} \mathrm{C}, 10$ mTorr) which gave a white crystalline solid on the cold finger and a purple residue in the pot. Crystals suitable for Xray crystallography were grown from hot toluene. Yield $=0.292 \mathrm{~g}$ $(89 \%) . T_{m}(D S C)=177^{\circ} \mathrm{C}$. Elemental analysis: Calcd for $\mathrm{C}_{17} \mathrm{H}_{22} \mathrm{AuF}_{5} \mathrm{~N}_{2}$ : C, 37.33; $\mathrm{H}, 4.026 ; \mathrm{N}, 5.13$; found $\mathrm{C}, 37.42 ; \mathrm{H}, 4.15 ; \mathrm{N}$, 4.99. ${ }^{1} \mathrm{H}-\mathrm{NMR}\left(300 \mathrm{MHz}, \mathrm{C}_{6} \mathrm{D}_{6}\right): \delta=2.55\left(\mathrm{~s}, 4 \mathrm{H}, \mathrm{CH}_{2}-\mathrm{CH}_{2}\right), 1.42[\mathrm{~s}$, $\left.18 \mathrm{H}, \mathrm{C}\left(\mathrm{CH}_{3}\right)_{3}\right] .{ }^{13} \mathrm{C}-\mathrm{NMR}\left(75.5 \mathrm{MHz}, \mathrm{C}_{6} \mathrm{D}_{6}\right): \delta=211.05$ (NCN), 56.44 $\left[\mathrm{C}\left(\mathrm{CH}_{3}\right)_{3}\right], 46.21\left(\mathrm{CH}_{2}-\mathrm{CH}_{2}\right), 31.25\left[\mathrm{C}\left(\mathrm{CH}_{3}\right)_{3}\right] .{ }^{19} \mathrm{~F}-\mathrm{NMR}(282.4 \mathrm{MHz}$, $\left.\mathrm{C}_{6} \mathrm{D}_{6}\right): \delta=-117.46\left(\mathrm{~m}\right.$, ortho-F), $-162.16\left(\mathrm{t},{ }^{3} \mathrm{~J}_{\mathrm{F}-\mathrm{F}}=20.1 \mathrm{~Hz}\right.$, para- $\left.\mathrm{F}\right)$, -165.12 (m, meta-F).

\section{Notes}

The authors declare no competing financial interest.

\section{Acknowledgments}

M. B. E. G. thanks the Natural Sciences and Engineering Research Council (NSERC) of Canada for funding through the Alexander Graham Bell CGS-D scholarship. T. Z. thanks Carleton University for the start-up grant (186853) and NSERC for funding (RGPIN-2016-06276). J. D. M. thanks NSERC for funding in the form of a discovery grant and acknowledges the Canada Foundation for Innovation (CFI) and Nova Scotia Research and Inno- 
vation Trust Fund for funding. S. T. B. acknowledges the Natural Sciences and Engineering Research Council of Canada (NSERC grant RGPIN-2014-06250) for funding.

Keywords: Atomic layer deposition . Precursor design . Gold · Structure elucidation · Ligand effects

[1] V. Miikkulainen, M. Leskelä, M. Ritala, R. L. Puurunen, J. Appl. Phys. 2013, 113, DOI https://doi.org/10.1063/1.4757907.

[2] M. B. E. Griffiths, P. J. Pallister, D. J. Mandia, S. T. Barry, Chem. Mater. 2016, 28, 44-46.

[3] M. Mäkelä, T. Hatanpää, K. Mizohata, J. Räisänen, M. Ritala, M. Leskelä, Chem. Mater. 2017, 29, 6130-6136.

[4] H. B. Profijt, S. E. Potts, M. C. M. van de Sanden, W. M. M. Kessels, J. Vac. Sci. Technol. A Vacuum, Surfaces, Film. 2011, 29, 050801.

[5] H. C. M. Knoops, J. W. Elam, J. A. Libera, W. M. M. Kessels, Chem. Mater. 2011, 23, 2381-2387.

[6] R. J. Puddephatt, I. Treurnicht, J. Organomet. Chem. 1987, 319, 129-137.

[7] J. Messelhäuser, E. B. Flint, H. Suhr, Appl. Surf. Sci. 1992, 54, 64-68.

[8] R. G. Parkhomenko, S. V. Trubin, A. E. Turgambaeva, I. K. Igumenov, J. Cryst. Growth 2015, 414, 143-150.

[9] K. Bernal Ramos, M. J. Saly, Y. J. Chabal, Coord. Chem. Rev. 2013, 257, 3271-3281.

[10] P. G. Gordon, A. Kurek, S. T. Barry, ECS J. Solid State Sci. Technol. 2015, 4 N3188-N3197.

[11] T. H. Baum, P. B. Comita, in Chem. Met. CVD (Eds.: T. T. Kodas, M. J. Hampden-Smith), Wiley-VCH Verlag $\mathrm{GmbH}$, Weinheim, Germany, 1994, pp. 303-327.

[12] A. Tamaki, J. K. Kochi, J. Organomet. Chem. 1973, 61, 441-450.

[13] M. M. B. Holl, P. F. Seidler, S. P. Kowalczyk, F. R. McFeely, Inorg. Chem. 1994, 33, 510-517.

[14] F. Jansen, T. Kruck, Adv. Mater. 1995, 7, 297-300.

[15] W. Mowat, A. Shortland, G. Yagupsky, N. J. Hill, M. Yagupsky, G. Wilkinson, J. Chem. Soc., Dalton Trans. 1972, 533.

[16] B. Wozniak, J. D. Ruddick, G. Wilkinson, J. Chem. Soc. A 1971, 3116-3120.

[17] J. S. Price, P. Chadha, D. J. H. Emslie, Organometallics 2016, 35, 168-180.

[18] L. G. Vaughan, W. A. Sheppard, J. Organomet. Chem. 1970, 22, 739-742.

[19] R. Usón, A. Laguna, M. Laguna, A. Usón, Inorg. Chim. Acta 1983, 73, 6366.

[20] H. Schmidbaur, R. Franke, Chem. Ber. 1975, 108, 1321-1328.

[21] J. P. Coyle, G. Dey, E. R. Sirianni, M. L. Kemell, G. P. A. Yap, M. Ritala, M. Leskelä, S. D. Elliott, S. T. Barry, Chem. Mater. 2013, 25, 1132-1138.

[22] J. P. Coyle, E. R. Sirianni, I. Korobkov, G. P. A. Yap, G. Dey, S. T. Barry, Organometallics 2017, 36, 2800-2810.

[23] M. B. E. Griffiths, S. E. Koponen, D. J. Mandia, J. F. McLeod, J. P. Coyle, J. J. Sims, J. B. Giorgi, E. R. Sirianni, G. P. A. Yap, S. T. Barry, Chem. Mater. 2015 27, 6116-6124.
[24] N. Boysen, T. Hasselmann, S. Karle, D. Rogalla, D. Theirich, M. Winter, T. Riedl, A. Devi, Angew. Chem. Int. Ed. 2018, 57, 16224; Angew. Chem. 2018 , 130, 2607-2609.

[25] M. K. Denk, A. Thadani, K. Hatano, A. J. Lough, Angew. Chemie Int. Ed. 1997, 36, 2607-2609.

[26] H. Schmidbaur, R. Franke, Angew. Chem. Int. Ed. 1973, 12, 416-417; Angew. Chem. 1973, 85, 449-450.

[27] S. Gaillard, P. Nun, A. M. Z. Slawin, S. P. Nolan, Organometallics 2010, 29, 5402-5408

[28] A. Battisti, O. Bellina, P. Diversi, S. Losi, F. Marchetti, P. Zanello, Eur. J. Inorg. Chem. 2007, 865-875.

[29] H. Schmidbaur, K. H. Raethlein, Inorg. Synth. 1978, 18, 141-142.

[30] See ref. ${ }^{[20]}$.

[31] J. M. López-de-Luzuriaga, M. Monge, M. E. Olmos, D. Pascual, T. Lasanta, Chem. Commun. 2011, 47, 6795.

[32] K. Arentsen, S. Caddick, F. G. N. Cloke, Tetrahedron 2005, 61, 9710-9715.

[33] E. A. V. Ebsworth, T. E. Fraser, D. W. H. Rankin, Chem. Ber. 1977, 110, 3494-3500.

[34] H. Schmidbaur, A. Schier, Chem. Soc. Rev. 2012, 41, 370-412.

[35] R. W. Baker, P. J. Pauling, J. Chem. Soc., Dalton Trans. 1972, 2264.

[36] W. G. Carden, J. Pedziwiatr, K. A. Abboud, L. McElwee-White, ACS Appl. Mater. Interfaces 2017, 9, 40998-41005.

[37] W. G. Carden, R. M. Thorman, I. Unlu, K. A. Abboud, D. H. Fairbrother, L. McElwee-White, ACS Appl. Mater. Interfaces 2019, 11, 11976-11987.

[38] A. Wuttke, M. Feldt, R. A. Mata, J. Phys. Chem. A 2018, 122, 6918-6925.

[39] G. V. Kunte, S. A. Shivashankar, A. M. Umarji, Meas. Sci. Technol. 2008, 19, 025704.

[40] J.-D. Chai, M. Head-Gordon, J. Chem. Phys. 2008, 128, 084106.

[41] J.-D. Chai, M. Head-Gordon, Phys. Chem. Chem. Phys. 2008, 10, 6615.

[42] C. C. Lovallo, M. Klobukowski, J. Comput. Chem. 2003, 24, 1009-1015.

[43] T. Zeng, M. Klobukowski, J. Chem. Phys. 2009, 130, 204107.

[44] C. Colominas, K. H. Lau, D. L. Hildenbrand, S. Crouch-Baker, A. Sanjurjo, J. Chem. Eng. Data 2001, 46, 446-450.

[45] R. Uson, A. Laguna, M. Laguna, D. A. Briggs, H. H. Murray, J. P. Fackler, Inorg. Synth. 2007, 26, 85-91.

[46] H. Schmidbaur, Inorg. Synth. 1978, 18, 135-140.

[47] See ref ${ }^{[2]}$.

[48] S. Barry, J. P. Coyle, T. J. Clark, J. J. M. Hastie, Group 11 Mono-Metallic Precursor Compounds and Use Thereof in Metal Deposition 2011, WO2012155264.

[49] M. L. J. Leutkens, A. P. Sattelberger, H. H. Murray, J. D. Basil, J. P. J. Fackler, Inorg. Synth. 1990, 28, 305.

Received: October 8, 2019 